\title{
Green Cooling of High Performance Microprocessors: Parametric Study Between Flow Boiling and Water Cooling
}

\author{
Jonathan A. Olivier \\ Jackson B. Marcinichen \\ Arnaud Bruch \\ John Thome \\ e-mail: john.thome@epfl.ch
}

Laboratoire de Transfert de Chaleur et de Mass, École Polytechnique Fédérale de Lausanne, Lausanne 1015, Switzerland

\begin{abstract}
Due to the increase in energy prices and spiralling consumption, there is a need to greatly reduce the cost of electricity within data centers, where it makes up to 50\% of the total cost of the IT infrastructure. A technological solution to this is using on-chip cooling with a singlephase or evaporating liquid to replace energy intensive air-cooling. The energy carried away by the liquid or vapor can also potentially be used in district heating, as an example. Thus, the important issue here is "what is the most energy efficient heat removal process?" As an answer, this paper presents a direct comparison of single-phase water, a 50\% water-ethylene glycol mixture and several two-phase refrigerants, including the new fourth generation refrigerants HFO1234yf and HFO1234ze. Two-phase cooling using HFCl34a had an average junction temperature from 9 to $15^{\circ} \mathrm{C}$ lower than for single-phase cooling, while the required pumping power for the central processing unit cooling element for single-phase cooling was on the order of 20-130 times higher to achieve the same junction temperature uniformity. Hot-spot simulations also showed that two-phase refrigerant cooling was able to adjust to local hot-spots because of flow boiling's dependency on the local heat flux, with junction temperatures being 20 to $30^{\circ} \mathrm{C}$ lower when compared to water and the $50 \%$ water-ethylene glycol mixture, respectively. An exergy analysis was developed considering a cooling cycle composed by a pump, a condenser, and a multimicrochannel cooler. The focus was to show the exergetic efficiency of each component and of the entire cycle when the subject energy recovery is considered. Water and HFC134a were the working fluids evaluated in such analysis. The overall exergetic efficiency was higher when using HFC134a (about 2\%), and the exergy destroyed, i.e., irreversibilities, showed that the cooling cycle proposed still have a huge potential to increase the thermodynamic performance. [DOI: 10.1115/1.4004435]
\end{abstract}

Keywords: flow boiling, microevaporators, refrigerant, electronics cooling, data centers, green, energy, exergy

\section{Introduction}

Reduction of primary energy consumption is strongly required to mitigate global warming caused by fossil fuel consumption. To achieve this objective, the use of waste heat thermal energy or renewable energy should be increased in energy conversion processes. Under the current efficiency trends, the energy usage of data centers in the United States is estimated to be more than $100 \times 10^{9} \mathrm{kWh}$ by 2011 , which represents an annual cost of approximately $\$ 7.4$ billion [1]. With the introduction of a proposed carbon tax in the United States [2], the annual costs could become as high as $\$ 1.4$ trillion by 2012 , increasing annually.

Cooling of data centers can represent up to $45 \%$ [3] of this total consumption using current cooling technologies (air cooling). In the United States, this relates to an estimated $45 \times 10^{9} \mathrm{kWh}$ usage by 2011 with an annual cost of $\$ 3.3$ billion or $\$ 4.6$ billion with the inclusion of carbon tax just for cooling. A problem with a data center is that all the electricity consumed is converted into heat, which, with current technologies, is rejected as waste into the atmosphere. Therefore, reusing this waste heat can potentially reduce not only the overall operating costs but also the carbon footprint of the data center.

Some solutions to this problem are to run server rooms at much higher temperatures, although at a risk of hardware failing sooner. Converting ac current to dc before entering the server room instead of converting it at each server might also help as rectifiers

Contributed by the Heat Transfer Division of ASME for publication in the Journal of Thermal Science and Engineering Applications. Manuscript received September 21, 2010; final manuscript received June 15, 2011; published online October 24, 2011. Assoc. Editor: Mehmet Arik. are generally inefficient and waste a lot of energy, rejected as heat in the data center. This, however, could be a very expensive solution requiring large-scale changes to the infrastructure. International Business Machines (IBM), on the other hand, has committed $\$ 1$ billion per year to increase the efficiency of IT systems with the launch of their project "Big Green" [4]. Their aim is to double the computing capacity of their data centres without increasing the power consumption within 3 years of inception.

One of the aspects mentioned in the IBM project is to exploit liquid cooling solutions, since implementing such technology could produce savings in energy of over 60\% [5]. Not only are liquid cooling solutions more efficient to air cooling but also air cooling has nearly reached its maximum cooling capacity. The maximum heat load for air cooling was reported to be around $370 \mathrm{~kW} / \mathrm{m}^{2}\left(37 \mathrm{~W} / \mathrm{cm}^{2}\right)$ [6], although higher heat fluxes of 600 $800 \mathrm{~kW} / \mathrm{m}^{2}\left(60-80 \mathrm{~W} / \mathrm{cm}^{2}\right)$ have been achieved [7] under carefully controlled conditions. To date, though, due to increasing package densities of CMOS circuit technologies, the ability to withdraw heat using air is becoming limited.

Another important objective in computing is 3D-IC architectures with integrated liquid and two-phase cooling. One such project, 3D Stacked Architectures with Interlayer Cooling (CMOSAIC), is underway involving six partners in Switzerland under the auspices of the Nano-Tera Initiative, where research is underway on cooling channels as small as $50 \mu \mathrm{m}$ [8].

Liquid and two-phase cooling have the advantage that heat can be reused in a secondary cycle as it is much easier to transport over distances than hot air. By allowing servers to run at higher temperatures or, rather, allowing servers to be cooled with fluids that are at a higher temperature, the added heat to the fluid could then be sold 


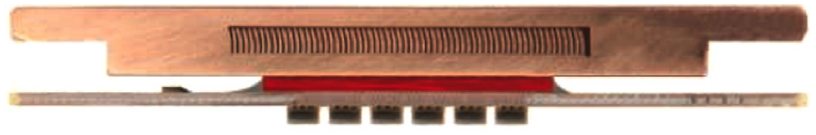

Fig. 1 Cross-sectional view of a cooling element used in Aquasar [19]

as usable energy, such as the heating of buildings, district heating, etc. Therefore, IT companies could also regain some of the electricity costs involved in operating these servers [9].

The challenge, though, is to cool the microchips efficiently at higher temperatures with heat fluxes in excess of $600 \mathrm{~kW} / \mathrm{m}^{2}(60$ $\mathrm{W} / \mathrm{cm}^{2}$ ) while maintaining the chip temperature below $85^{\circ} \mathrm{C}$. Chu et al. [10], and more recently Agostini et al. [11], have surveyed current cooling technologies that might have the capability of reaching these demands. Some of these technologies include single-phase microchannel cooling, spray cooling, and two-phase microchannel cooling, with microchannel two-phase cooling being the most promising solution. This is due to it having the lowest power consumption for the same amount of heat removal.

Single-phase microchannel chip cooling has its apparent advantage in that it is relatively easy to use. Numerous research has been performed in this area, such as that of Celata et al. [12-15], Tuckerman and Pease [16], and Colgan et al. [17,18] to name but a few, with the technology being well understood. This technology is currently being used in the recently started Aquasar [19], which is an IBM blade center converted to make use of a water-cooled cycle. Figure 1 depicts a cross-sectional photograph of the split flow, multimicrochannel cooling element on the central processing unit (CPU) designed by the Laboratoire de Transfert de Chaleur et de Masse (LTCM) laboratory and fabricated by Wolverine Tube, Inc., that is used in this system. Even so, while water has many advantages over air cooling, it has some disadvantages in that it requires a high pumping power to keep temperature gradients on the microprocessor to within acceptable limits. Furthermore, water presents a problem with its high freezing point (hence system is charged after installation), microbe potential formation, corrosive properties, electrical conductivity, and erosive nature due to high fluid velocities. Hence, the future competitor to a water-cooled system is a two-phase refrigerant cooled system.

Two-phase microchannel flow takes advantage of the latent heat of the fluid, which is much more effective in removing heat than when using the sensible heat of a single-phase fluid. The latent heat also implies that chip temperatures are much more uniform. Research in this area, although not as extensive and understood as single-phase flow, has also received a lot of attention in the past few years. The works of Kandlikar and co-workers [20-22], Celata et al. [23], Garimella and co-workers [24-27], Bergles and coworkers [28,29], Thome et al. [30-33], and Jensen et al. [34,35] have promoted most of the work in this area. It has been shown that heat fluxes as high as $3500 \mathrm{~kW} / \mathrm{m}^{2}\left(350 \mathrm{~W} / \mathrm{cm}^{2}\right)$ can be achieved using a refrigerant [36] in parallel multimicrochannel cooling elements. It was further shown that the heat fluxes of $1800 \mathrm{~kW} / \mathrm{m}^{2}$ $\left(180 \mathrm{~W} / \mathrm{cm}^{2}\right)$ can be removed with a saturation temperature as high as $60^{\circ} \mathrm{C}$, while maintaining the chip temperature below $85^{\circ} \mathrm{C}$ [37]. A refrigerant, has the advantage of being a dielectric fluid with a long successful history in industrial applications, is inert to most engineering materials, readily available, and relatively inexpensive. New refrigerants also have a negligible impact on the environment.

Single-phase cooling, because of its simplicity, seems to currently be the front runner for cooling electronic chips. However, due to its large pumping power requirements and exergy destroyed relative to two-phase refrigerants, this method might not be the most "green" option. Therefore, the main objective of this paper is to compare single-phase cooling to two-phase microchannel cooling on a one-to-one basis. This will be done by means of simulations incorporating the latest single-phase and two-phase microchannel models. Water and a $50 \%$ water-glycol mixture will be used as the single-phase fluids. For two-phase cooling, seven refrigerants will be simulated, which include the new fourth generation refrigerants HFO1234yf and HFO1234ze, seen as potential replacements of HFC134a. The analysis will be based on the first and second law of thermodynamics, the latter permitting a better understanding of the irreversibilities inherent of each cooling strategy. To simplify the interpretation, an exergy analysis will be done on a hypothetical cooling cycle considering as objective function the exergy recovered in the condenser.

\section{Description of Software}

The simulation code was written in such a way as to give the user the ability to simulate multichannel flow boiling or liquid cooling. It gives the user the option to customize all the input parameters, such as channel width, fin height, fin thickness, evaporator width, length, base thickness, and the material it is made from. An inlet loss coefficient can also be defined for calculating the losses due to an inlet slit (orifice), usually used for two-phase cooling for stability reasons.

Fluids included are those obtained from the REFPROP [38] database, as well as non-REFPROP fluids, such as water-ethylene glycol (EG) mixtures and FC72. Other user inputs are heat flux, mass flux/flow rate, inlet saturation pressure, subcooling, and inlet quality if there is no subcooling.

With these properties set, models can be selected in a plug-andplay fashion. A wide selection of models exists for single-phase heat transfer and pressure drop (laminar and turbulent flow) and for microchannel two-phase flow. These latter ones include heat transfer, pressure drop, critical heat flux, and two-phase flow pattern map models.

A flow diagram of the program is given in Fig. 2. The program calculates local values by discretizing the length of the cooling element. For a multichannel element, only one channel and its half fins are analyzed by making use of the fin efficiency. This assumes that there is no maldistribution of the flow within the system. Furthermore, no loss of heat at the boundaries (to the ambient) is assumed. The program then steps through each node, calculating the local pressure, heat transfer coefficient, fin efficiency, and wall heat flux. Fluid properties are then calculated and the fluid state determined from which the correct models are used accordingly. After the calculations are performed at each node, wall and junction temperatures are calculated, as well as the critical heat flux for two-phase flows.

For the purpose of this study, mechanistic models will be used where possible. For this reason, the three-zone model [30] for twophase heat transfer will be used since it was shown to predict many fluids and geometries with good accuracy [39]. The numerically based model of Revellin and Thome [31] will be used for critical heat flux calculations. For two-phase pressure drops, the model of Cioncolini et al. [40], in combination with the model by MüllerSteinhagen and Heck [41], will be used. The local use of these two methods is determined by making use of the flow pattern map predictions of Ong [42]. The model by Cioncolini et al. is an annular flow pressure drop model, while the model by Müller-Steinhagen and Heck was found to predict microchannel pressure drops with good accuracy [43]. Laminar heat transfer and friction factors will be calculated by means of the simultaneously developing flow correlations for rectangular channels of Shah and London [44], which are also summarized by Thome [45]. All these models have been compared to a wide range of experimental data from numerous laboratories around the world with an excellent agreement and will therefore not be compared in this paper again.

Assumptions made are (1) the evaporator is uniformly heated from the bottom with a base heat flux of $q_{b}$, (2) the flow through the cooler is uniformly distributed between all the channels, (3) the top of the cooler is adiabatic, and (4) the heat transfer is one dimensional. These assumptions were made to simplify the analysis and highlight the potential that such simulations can have on preliminary design of microevaporators. Although uniform heat fluxes are not found in real electronic components, it lends itself 


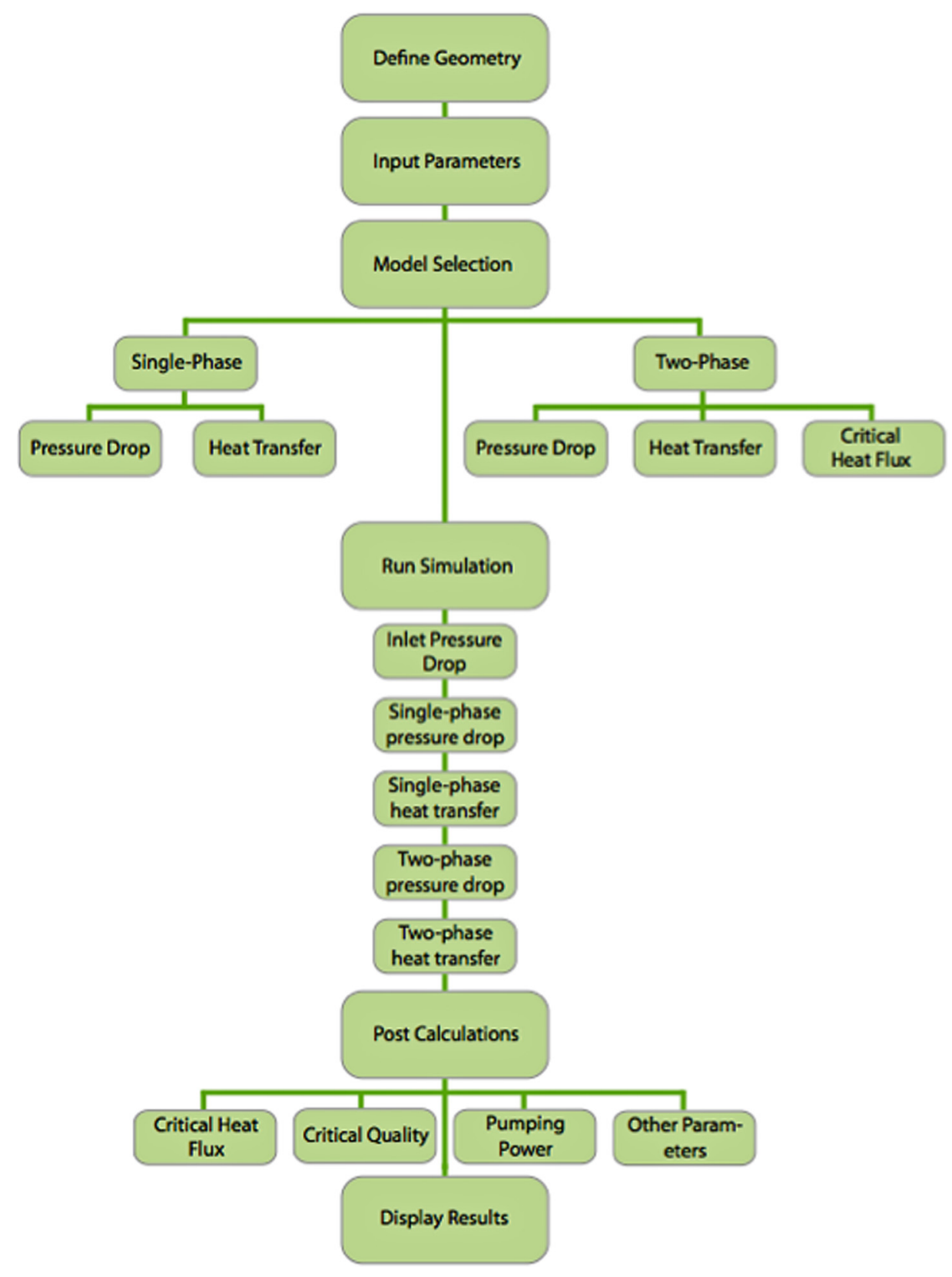

Fig. 2 Flow diagram of simulation program

to better interpretation of the results with regards to the correlations used. It further also acts as a reference point to nonuniform heat fluxes, which will also be discussed in this paper.

\section{Simulation Paradigm}

A schematic of the channels is given in Fig. 3. The hypothetical evaporator (and CPU) will have a footprint of $20 \mathrm{~mm} \times 20 \mathrm{~mm}$. A base thickness of $1 \mathrm{~mm}$ will be assumed, with the material of the evaporator being copper. The evaporator will have fins having a height of $1.7 \mathrm{~mm}$ and fin-thickness of $170 \mu \mathrm{m}$, while the channels will have a width of $170 \mu \mathrm{m}$. For two-phase stability reasons, an inlet loss coefficient of 25 will be assumed for pressure drop of the micro-orifices at the entrance of each channel but will not be present for the single-phase simulations (although some sort of restriction would be required to prevent mal-distribution).

Heat fluxes will be varied between 200 and $1500 \mathrm{~kW} / \mathrm{m}^{2}$ and mass fluxes between 300 and $1000 \mathrm{~kg} /\left(\mathrm{m}^{2} \mathrm{~s}\right)\left(300-6000 \mathrm{~kg} /\left(\mathrm{m}^{2} \mathrm{~s}\right)\right.$ for single-phase fluids). Since the main application for the cooling of microprocessors in a green environment will be to redistribute the heat generated, the fluid inlet temperature will be fixed at $60^{\circ} \mathrm{C}$ such that the heat rejected will be available at about $50-55^{\circ} \mathrm{C}$. The main challenge is then to maintain the junction temperature, $T_{j}$, below $85^{\circ} \mathrm{C}$. This implies that, with high heat fluxes and a low overall temperature difference between the fluid and the junction, a high heat transfer coefficient on the fluid side will be required. As an example, using the maximum heat flux for this simulation $\left(1500 \mathrm{~kW} / \mathrm{m}^{2}\right.$ or $150 \mathrm{~W} / \mathrm{cm}^{2}$ ) and a temperature difference of $25^{\circ} \mathrm{C}$ between the junction and coolant, fluid heat transfer coefficients on the order of $7000 \mathrm{~W} /\left(\mathrm{m}^{2} \mathrm{~K}\right)$ would be needed. For a copper evaporator with a base thickness of $1 \mathrm{~mm}$, the equivalent temperature difference between the base and the channel walls will be in the order of $3.8^{\circ} \mathrm{C}$, making its resistance comparatively unimportant for the requirements of the package. It should be noted that these simulations do not consider the thermal interface material (TIM) between the silicon die and the micro-evaporator, which will have a significant effect on the overall thermal resistance path if chosen badly. The reason for not using a TIM is so that the results obtained can be used as a reference, since there are many aspects of TIMs that influence its 


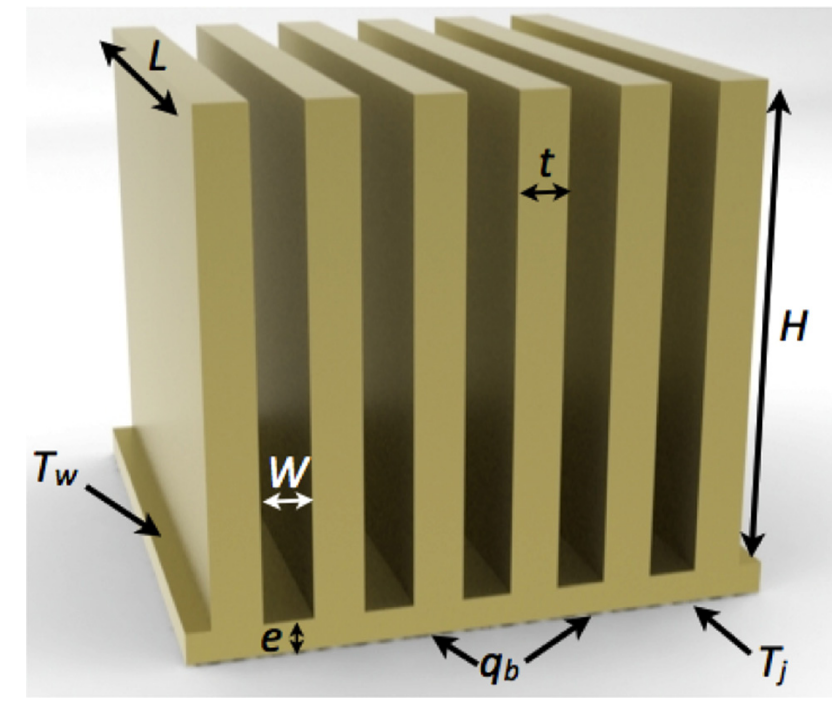

Fig. 3 Schematic of a multichannel micro-evaporator

resistance, such as its thickness, how well it is spread over the die, the amount of pressure exerted on the die, etc. Therefore, the junction temperature and evaporator base temperature are the same.

Nine fluids will be tested and compared, seven of which are refrigerants, the other two being pure water and a 50\% water-EG mixture. Ethylene glycol is of interest since it is added to water where environments are such that freezing becomes a concern. Ozone depletion [46] and global warming [47] protocols have led to the development of the so-called fourth generation refrigerants having a zero ozone depleting potential and a very low global warming potential. Two of these refrigerants are HFO1234yf and HFO1234ze, seen as replacement refrigerants for HFC134a. The first is primarily targeted for automotive air-conditioning systems while the second is targeted for electronic cooling applications. Properties of the working fluids are listed in Table 1.

\section{Results}

4.1 Single-Phase Cooling. Figure 4 gives the local heat transfer coefficients for various mass fluxes when the base heat flux is $1000 \mathrm{~kW} / \mathrm{m}^{2}\left(100 \mathrm{~W} / \mathrm{cm}^{2}\right)$. For mass fluxes below $3400 \mathrm{~kg} /$ $\left(\mathrm{m}^{2} \mathrm{~s}\right)$, the heat transfer coefficients are a function of the axial distance along the channel length, while above this value, they are not. This is due to the fact that the flow inside the channel is classified as laminar below this value, while it is turbulent above it. For laminar flow, the dependence of the heat transfer coefficient on the axial distance from the entrance is due to the growing laminar thermal boundary layer [44], which produces higher heat transfer coefficients than when the flow is fully developed. Although turbulent flow has a thermal entry length, which for water is approximately 10 tube diameters, the increase in heat transfer is approximately 5\% higher than the fully developed value and was thus not incorporated in the current simulation. Further, single-phase turbulent flow is generally not encountered in microchannels, which in turn requires huge amount of pumping power to achieve. Similar results are obtained for the waterethylene glycol mixture in Fig. 5, except that turbulent flow is never reached for the highest mass flux tested, which is due to the viscosity being much higher than that of pure water.

Figure 6 gives the length-averaged heat transfer coefficients for water as a function of the base heat flux for various mass fluxes. It is seen that the heat transfer coefficients are independent of the heat flux and dependent on the mass flux, typical for single-phase flow. It would be expected that the fluid properties of the singlephase fluid would change significantly with the heat flux due to the increase in fluid temperature. However, since the main heat transfer mode in laminar flow is conduction, the only physical property that influences the heat transfer coefficient is the thermal conductivity. In the extreme case, which occurs at the lowest mass flux, the thermal conductivity varies by less than $3 \%$ for a temperature difference from inlet to outlet of approximately $30^{\circ} \mathrm{C}$. Therefore, the effect that heat flux has on heat transfer coefficient is negligible. This is also very clearly seen in Fig. 7 showing the graphs of the dimensionless distance, $\mathrm{z}$ (viz. Eq. (1)), as a function of the Nusselt number for heat fluxes varying from 200 to 1500 $\mathrm{kW} / \mathrm{m}^{2}\left(20-150 \mathrm{~W} / \mathrm{cm}^{2}\right)$ and mass fluxes from 300 to $2800 \mathrm{~kg} /$ $\left(\mathrm{m}^{2} \mathrm{~s}\right)$ (all the laminar data). What seems like a solid line is all the data, showing a single-phase fluid's independence on heat flux. The dimensionless distance is defined as

$$
z^{+}=\frac{z}{\operatorname{Re} \operatorname{Pr} D}
$$

Similar results are found for the EG mixture. By comparing the water and EG mixture, it is noticed that water always has higher heat transfer coefficients for the same mass flux, which is related to the higher channel Reynolds numbers obtained for water.

4.2 Two-Phase Cooling. Figure 8 shows the local heat transfer coefficients as a function of the local vapor quality for various mass fluxes for HCFC123 for a heat flux of $1000 \mathrm{~kW} / \mathrm{m}^{2}(100$ $\mathrm{W} / \mathrm{cm}^{2}$ ). The heat transfer coefficient has a very low dependence on mass flux. This is in conjunction to nearly all studies indicating the lack of influence of mass flux for microchannel boiling [39].

Critical heat flux is an important design limitation aspect of micro-evaporators for the cooling of high heat flux electronics since it is related to the maximum possible heat flux attainable for

Table 1 Basic fluid and environmental properties of working fluids at $\boldsymbol{T}_{\text {sat }}=25^{\circ} \mathrm{C}$

\begin{tabular}{|c|c|c|c|c|c|c|c|c|c|}
\hline & HFC134a & HFO1234yf ${ }^{a}$ & $\mathrm{HFO}_{1234 \mathrm{ze}^{\mathrm{a}}}$ & HCFC123 & HFC236fa & HFC245fa & CFC114 & Water & $50 \% \mathrm{EG}$ \\
\hline $\mathrm{GWP}^{\mathrm{b}}$ & 1320 & 4 & 6 & 76 & 9650 & 1020 & 9880 & - & - \\
\hline ODP & 0 & 0 & 0 & 0.012 & 0 & 0 & 0.94 & - & - \\
\hline Atmospheric Lifetime (years) & 14 & $0.030^{\mathrm{c}}$ & $0.038^{\mathrm{d}}$ & 1.3 & 240 & 7.6 & 300 & - & - \\
\hline Boiling point @ 1 bar $\left({ }^{\circ} \mathrm{C}\right)$ & -26.1 & -29 & -19 & 27.5 & -1.4 & 15.1 & 3.6 & - & - \\
\hline Triple point $\left({ }^{\circ} \mathrm{C}\right)$ & -103.3 & -150.4 & -150.4 & -107 & -93.6 & -102 & -92.5 & - & - \\
\hline$\rho_{l}\left(\mathrm{~kg} / \mathrm{m}^{3}\right)$ & 1207 & 1094 & 1180 & 1464 & 1360 & 1339 & 1518 & 997 & 1034 \\
\hline$\rho_{v}\left(\mathrm{~kg} / \mathrm{m}^{3}\right)$ & 32.4 & 37.6 & - & 5.9 & 18.4 & 8.6 & 7.8 & - & - \\
\hline$h_{l v}\left(\mathrm{~kg} / \mathrm{m}^{3}\right)$ & 177.8 & $149^{\mathrm{e}}$ & $195^{\mathrm{e}}$ & 171.4 & 145.9 & 190.3 & 135.9 & - & - \\
\hline$\mu_{l},(\mu \mathrm{Pa} \mathrm{s})$ & - & - & - & - & - & - & - & 890 & 4900 \\
\hline$k_{l}(\mathrm{~mW} /(\mathrm{m} \mathrm{K}))$ & - & - & - & - & - & - & - & 607.2 & 382.0 \\
\hline$c_{p}(\mathrm{~kJ} /(\mathrm{kg} \mathrm{K}))$ & - & - & - & - & - & - & - & 4.18 & 3.64 \\
\hline
\end{tabular}

${ }^{\text {a }}$ Classified fluid. All properties obtained from sources available in the public domain.

${ }^{\mathrm{b}} 100$ year integration time horizon (ITH), $\mathrm{CO}_{2}=1$.

${ }^{\mathrm{c}}$ Nielsen et al. [48].

${ }^{\mathrm{d}}$ Søndergaard et al. [49].

${ }^{\mathrm{e}}$ Estimate from Brown et al. [50]. 


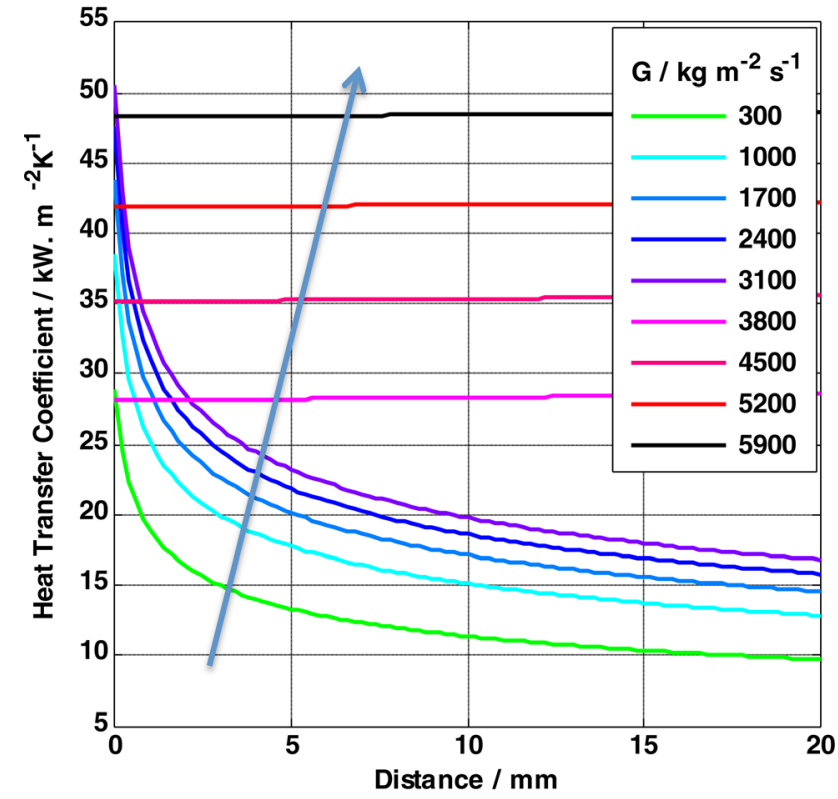

Fig. 4 Local heat transfer coefficients for water for various mass fluxes

a given mass flux before dryout starts to occur. Critical heat flux is a strong function of the mass flux, length of the channel, as well as fluid properties. Although the simulations were run for various imposed heat fluxes, this does not necessarily imply that the fluid is capable of reaching these values. Figure 9 shows the base critical heat fluxes as a function of the imposed base heat flux for various mass fluxes for HFC134a. The figure shows that the critical heat flux is a strong function of the mass flux. This is understandable since lower mass fluxes would imply that local dryout occurs at lower vapor qualities for a given heat flux. Therefore, only for mass fluxes greater than $700 \mathrm{~kg} /\left(\mathrm{m}^{2} \mathrm{~s}\right)$ will the evaporator be able to be used safely for the whole range of base heat fluxes since the critical heat flux does not drop below the given base heat flux.

Critical heat flux simulations were performed for all the refrigerants, with the results shown in Fig. 10. To ease the readability of the graphs, only the lowest and highest mass fluxes are shown.

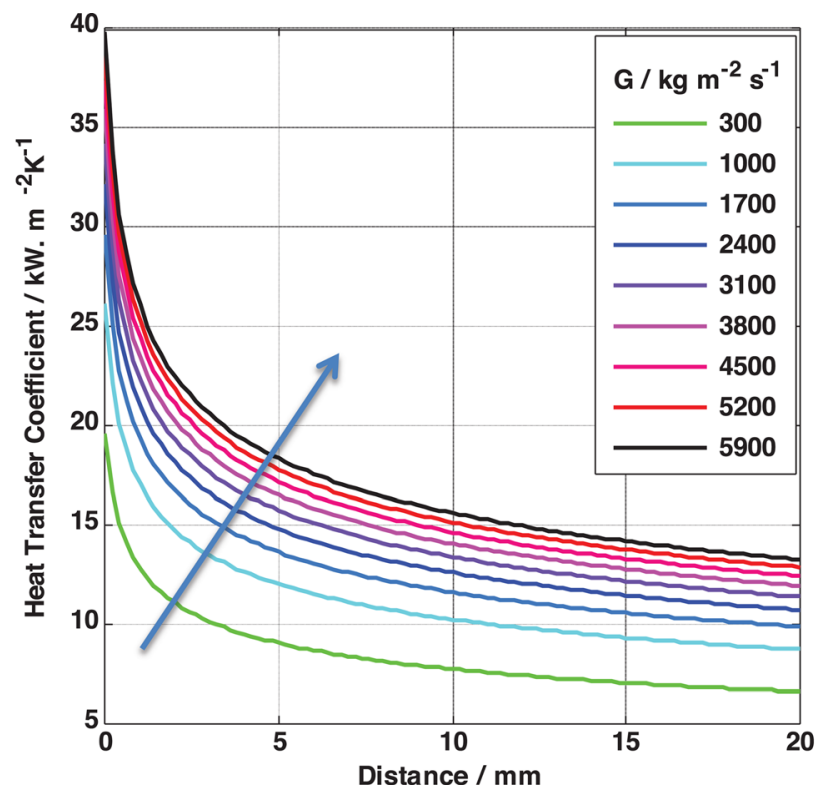

Fig. 5 Local heat transfer coefficients for $50 \%$ water-ethylene glycol mixture for various mass fluxes

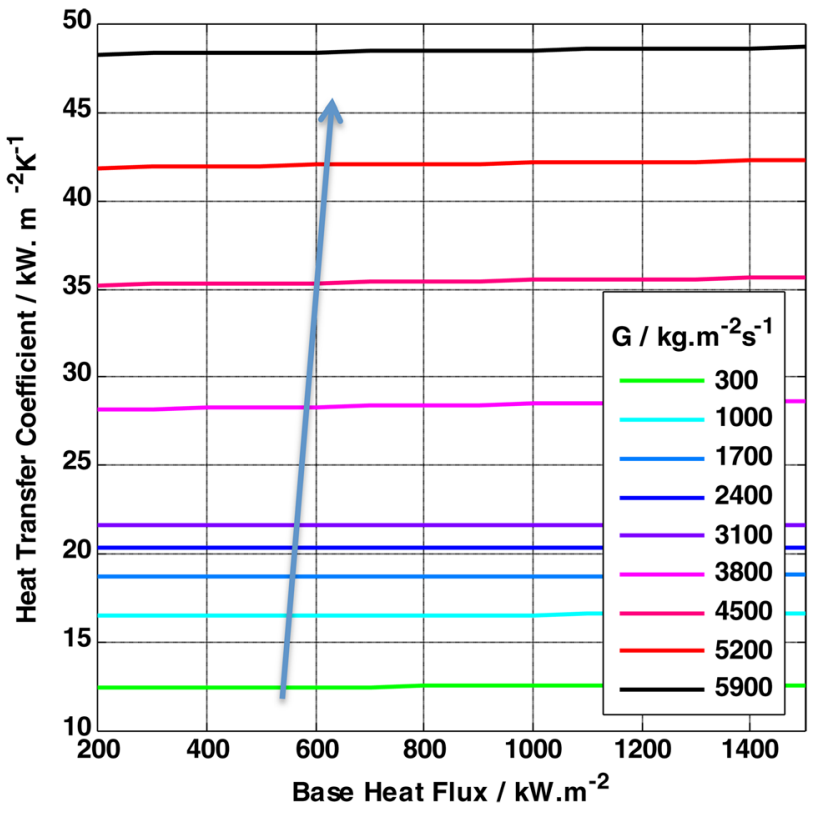

Fig. 6 Length-averaged heat transfer coefficients for water as a function of the base heat flux for various mass fluxes

The dashed lines denote a mass flux of $300 \mathrm{~kg} /\left(\mathrm{m}^{2} \mathrm{~s}\right)$ and the solid lines $1000 \mathrm{~kg} /\left(\mathrm{m}^{2} \mathrm{~s}\right)$. It is of interest to note that the best performing refrigerants with regard to maximum possible heat flux for the given geometry are HCFC123 and HFC245fa. This is partially due to the higher surface tension forces of these fluids (almost double the rest). The larger the surface tension, the more vapor shear is required to remove the liquid film from the wall. The density difference between liquid and vapor also has a significant effect on dryout. The higher this difference, the greater the difference in liquid and vapor velocities and the smaller the interfacial waves will be. Thus, the liquid film can become much thinner before the interfacial waves become the same height as the film thickness, which will then cause dryout [31].

For this case study, mass fluxes should be equal to or greater than $900 \mathrm{~kg} /\left(\mathrm{m}^{2} \mathrm{~s}\right)$ if all the refrigerants are to operate below the critical heat flux level for all base heat fluxes. Of course, the critical heat fluxes can be increased by changing the flow configuration such that the flow inlet is at the center of the microevaporator and the exits at the two-ends (split flow configuration).

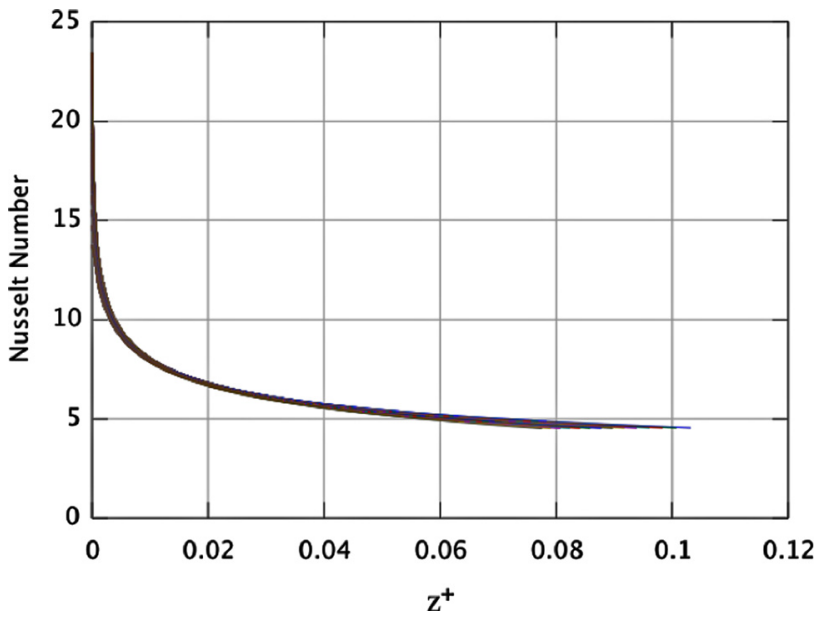

Fig. 7 Nusselt number for water for all the heat fluxes and mass fluxes simulated as a function of the dimensionless distance 


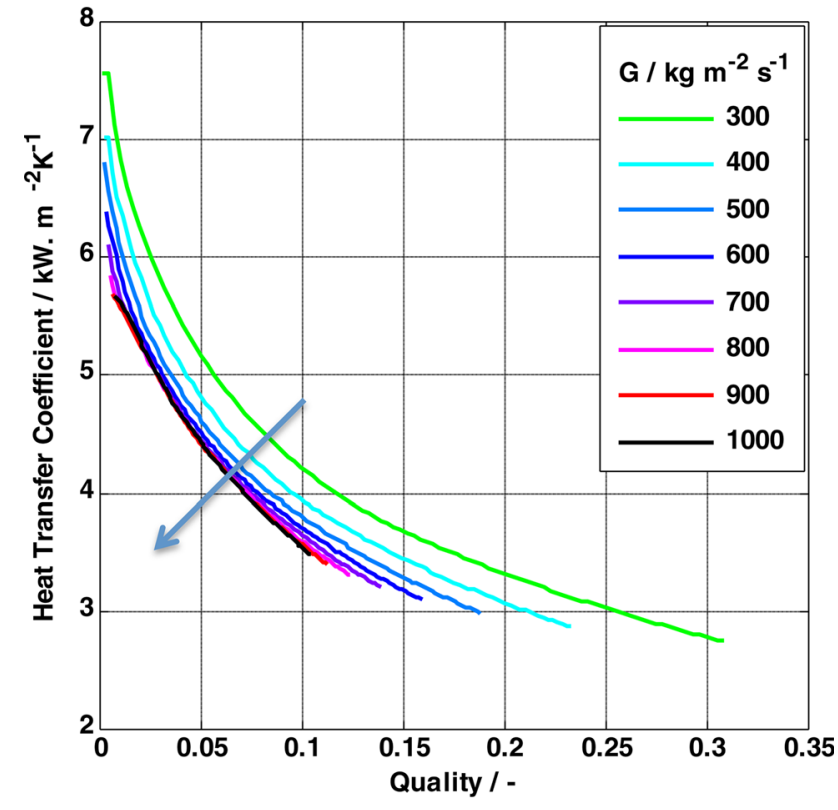

Fig. 8 Local heat transfer coefficients for HCFC123 as a function of the local vapor quality for various mass fluxes

This has the effect of halving the heated length, which then increases the critical heat flux [31]. Lower pressure drops are also achieved by making use of such a configuration [51].

\subsection{Single-Phase Versus Two-Phase Cooling}

4.3.1 Heat Transfer Coefficients. Figure 11 shows the lengthaveraged heat transfer coefficients as a function of the base heat flux for a mass flux of $900 \mathrm{~kg} /\left(\mathrm{m}^{2} \mathrm{~s}\right)$ for all the fluids. For the refrigerants, HFC134a performs the best followed by HFO1234yf, HFO1234ze, HFC236fa, HFC245fa, CFC114, and last HCFC123. This is mostly due to the saturation pressures or rather the reduced pressure of the fluids influencing the bubble pair frequency, which in turn influences the vapor quality where the cyclical onset of dryout in the three-zone elongated bubble heat transfer model occurs [39]. The greater the reduced pressure, the higher the bubble pair

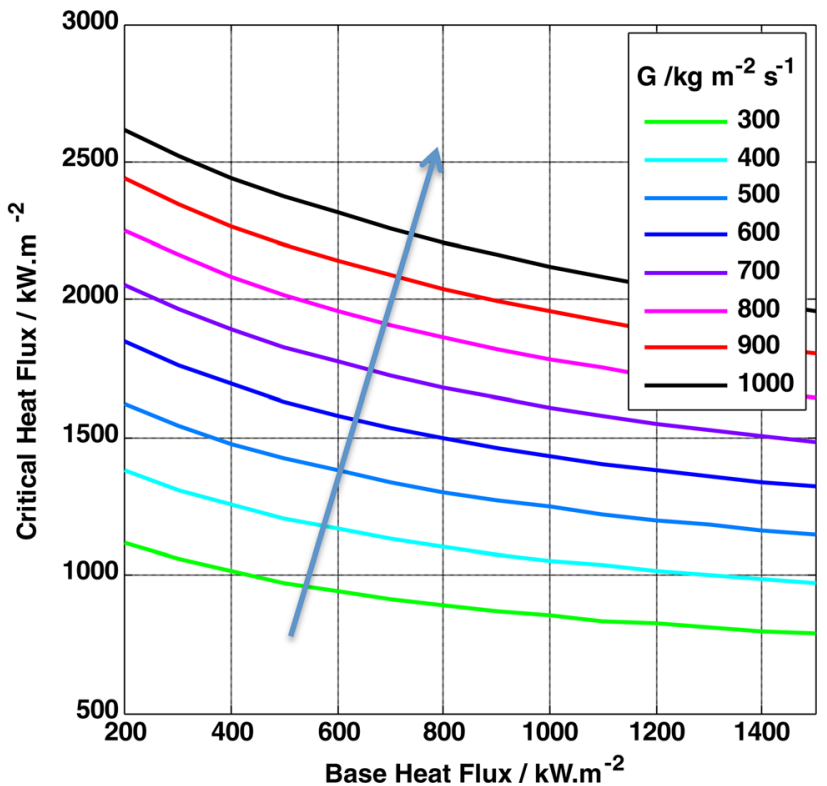

Fig. 9 Critical heat flux of HFC134a for various heat and mass fluxes

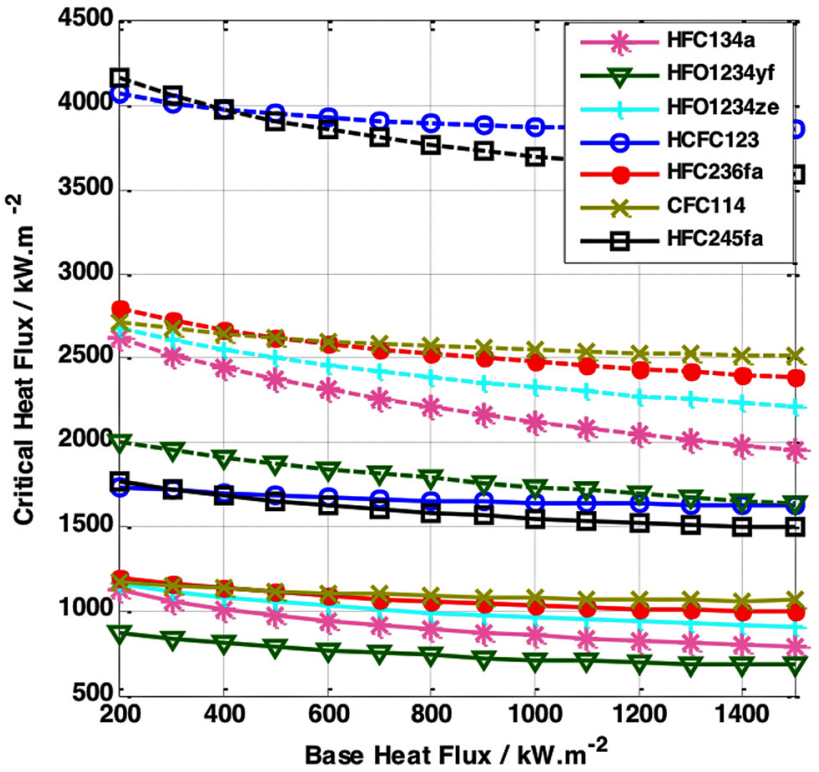

Fig. 10 Critical heat flux of all the refrigerants as a function of the heat flux for a mass flux of $300 \mathrm{~kg} /\left(\mathrm{m}^{2} \mathrm{~s}\right)$ and $1000 \mathrm{~kg} /\left(\mathrm{m}^{2} \mathrm{~s}\right)$

frequency and the higher the onset of cyclical dryout quality. The heat transfer coefficient starts to decrease once this quality is reached. The critical pressures of all the fluids were more or less in the same range, varying from 32 to 40 bar. Therefore, with HCFC123 having the lowest saturation pressure, and hence the lowest reduced pressure, it also has the lowest bubble pair frequency, with the onset of cyclical dryout occurring at lower qualities, and hence lower heat transfer coefficients. It should be noted that the reduced pressure of HFO1234yf is slightly higher than that of HFC134a, but due to its lower heat of vaporization and liquid density value, the amount of time a liquid film of the bubble is present is less and onset of cyclical dryout occurs earlier.

The single-phase fluids heat transfer coefficients are almost always higher than most of the refrigerants at low heat fluxes. HFC134a has a higher value for heat fluxes greater than $700 \mathrm{~kW} /$ $\mathrm{m}^{2}\left(70 \mathrm{~W} / \mathrm{cm}^{2}\right)$. This, as discussed in Sec. 4.2 , is due to the heat

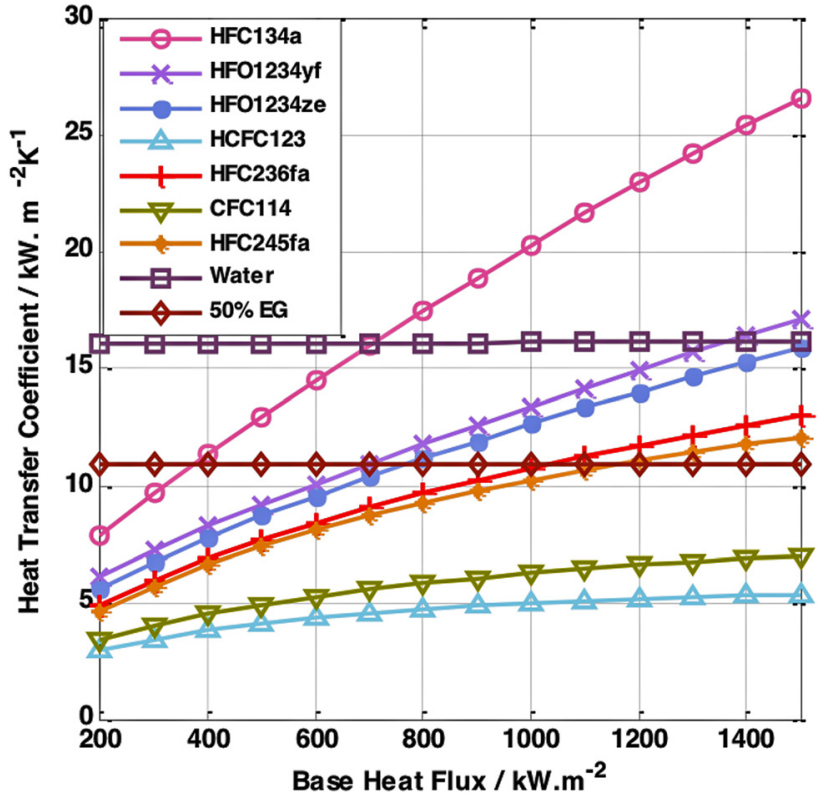

Fig. 11 Heat transfer coefficients as a function of the base heat flux 


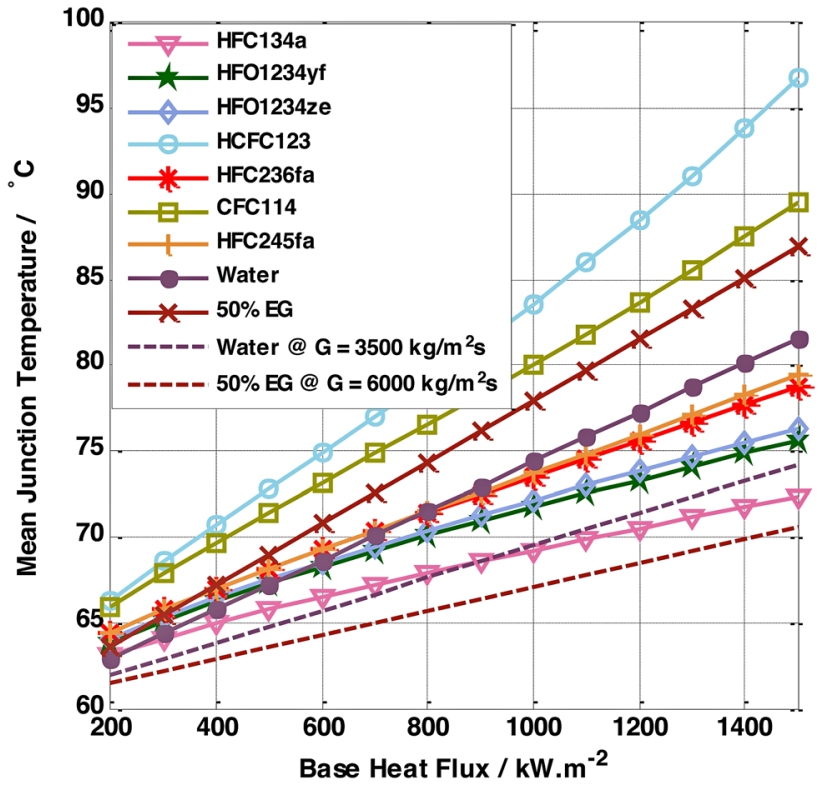

Fig. 12 Junction temperature as a function of the base heat flux for a mass flux of $900 \mathrm{~kg} /\left(\mathrm{m}^{2} \mathrm{~s}\right)$

transfer coefficient of single-phase flow not being a function of the heat flux, which is the case for two-phase boiling. There are two more reasons for the higher heat transfer coefficients. The heat transfer mode in laminar flow is purely through conduction. Water has a thermal conductivity of almost an order of a magnitude greater than any of the refrigerants. Further, laminar flow heat transfer in conventional tubes/channels is always a few orders of magnitude lower than evaporation heat transfer. However, for very small diameter channels, as those presented here, the heat transfer coefficients become very large, to the extent that they are of the same order of magnitude as that of evaporation/boiling.

4.3.2 Junction Temperature and Temperature Uniformity. Figure 12 shows the length-averaged temperature of the junction of the micro-evaporator, which is calculated from the wall temperature plus the conductive temperature difference across the copper die of $1 \mathrm{~mm}$ thickness. This figure shows the results for two-phase refrigerants, single-phase water, and EG at a mass flux of $900 \mathrm{~kg}$ / $\left(\mathrm{m}^{2} \mathrm{~s}\right)$. Also included are the junction temperatures of water and EG for a mass flux of 3500 and $6000 \mathrm{~kg} /\left(\mathrm{m}^{2} \mathrm{~s}\right.$ ) (dashed lines), respectively. The junction temperature is below $85^{\circ} \mathrm{C}$ for all fluids below a heat flux of $1050 \mathrm{~kW} / \mathrm{m}^{2}\left(105 \mathrm{~W} / \mathrm{cm}^{2}\right)$, after which HCFC123 exceeds this limit. This applies for CFC114 at heat fluxes above $1250 \mathrm{~kW} / \mathrm{m}^{2}\left(125 \mathrm{~W} / \mathrm{cm}^{2}\right)$ and EG above $1400 \mathrm{~kW} /$ $\mathrm{m}^{2}\left(140 \mathrm{~W} / \mathrm{cm}^{2}\right)$. These temperatures are directly related to the heat transfer coefficients in Fig. 11. Thus, HFC134a has the lowest junction temperature over the range of heat fluxes, followed by HFO1234yf and HFO1234ze.

Another thermal design criterion to consider is the uniformity of the junction (chip) temperature. This is an important aspect with regard to the cooling of integrated circuits as too high a temperature gradient over the axial length of the surface of a silicon chip will create an adverse nonuniform thermal stress. This could lead to the chip being damaged, as silicon is very brittle. The temperature uniformity can be expressed by taking the standard deviation of all the temperatures at the junction along the length of the channel calculated for a specific mass flux and all heat fluxes. This is shown in Fig. 13. The overall trend is a decrease in uniformity with an increase in heat flux. Once again, HFC134a has the best temperature uniformity, with temperature variations of less than $2{ }^{\circ} \mathrm{C}$ at the maximum base heat flux, while HCFC123 is the worst. The single-phase fluids are generally worse than most of the refrigerants. Only after increasing the mass fluxes in excess

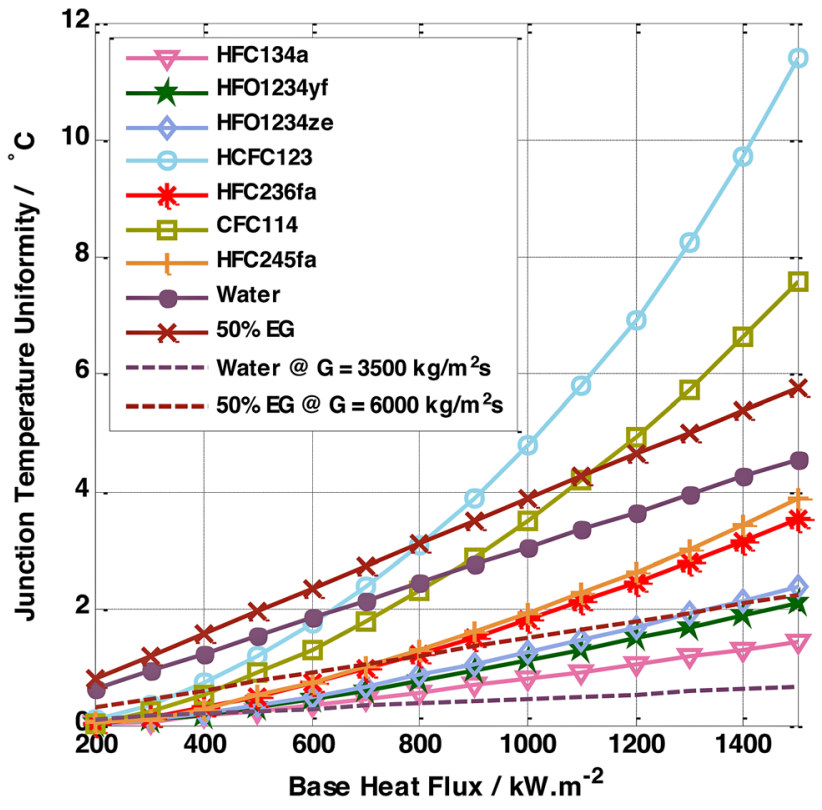

Fig. 13 Junction temperature uniformity as a function of the base heat flux for a mass flux of $900 \mathrm{~kg} /\left(\mathrm{m}^{2} \mathrm{~s}\right)$

of $3500 \mathrm{~kg} /\left(\mathrm{m}^{2} \mathrm{~s}\right)$ for water and $6000 \mathrm{~kg} /\left(\mathrm{m}^{2} \mathrm{~s}\right)$ for EG do the uniformities become comparable (dashed lines in figure). This is a tremendous mass flux and will have a huge impact on pumping power requirements. It should be noted that, for water, the uniformity was still worse than HFC134a for a mass flux of $3400 \mathrm{~kg}$ / $\left(\mathrm{m}^{2} \mathrm{~s}\right)$. The only reason why it improved so much for a mass flux of $3500 \mathrm{~kg} /\left(\mathrm{m}^{2} \mathrm{~s}\right)$ is because the flow became turbulent.

4.3.3 Pressure Drop and Pumping Power. Figures 14 and 15 show the pressure drops and corresponding pumping powers in pressure/flow rates as a function of the base heat flux for all the fluids. Figure 14 shows that there is an increase in pressure drop with an increase in base heat flux for the refrigerants. This is due to higher outlet qualities being reached, where pressure gradients are greater for higher heat fluxes. For single-phase water and EG, the opposite is seen where the pressure drop decreases slightly for

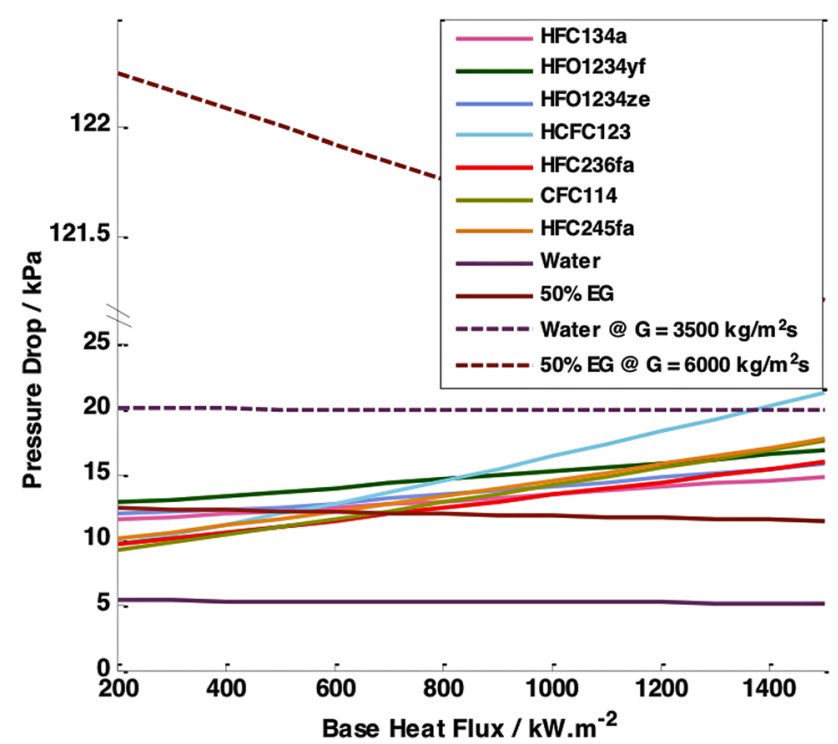

Fig. 14 Pressure drop as a function of the base heat flux for a mass flux of $900 \mathrm{~kg} /\left(\mathrm{m}^{2} \mathrm{~s}\right)$ 


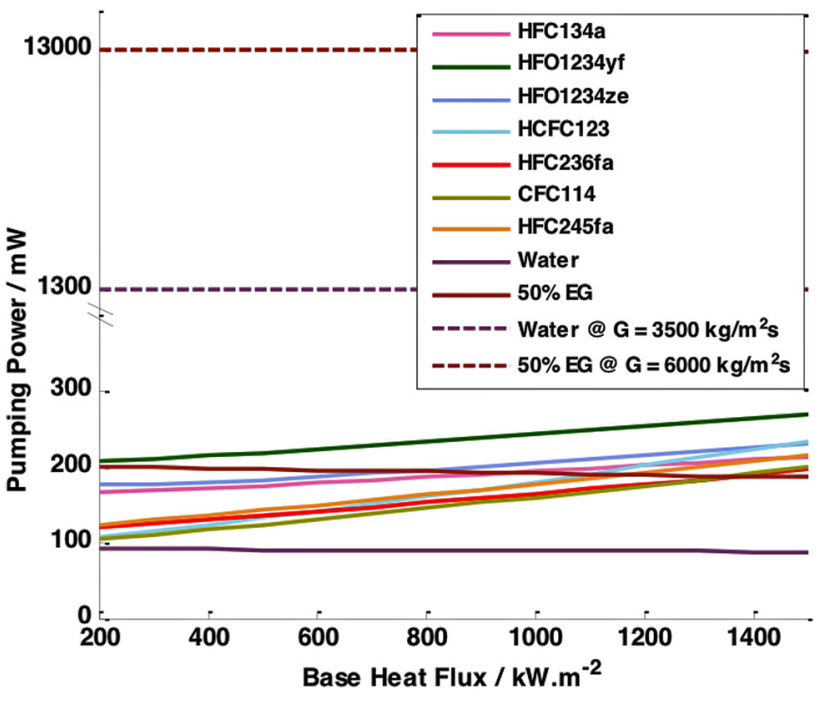

Fig. 15 Required pumping power as a function of the base heat flux for a mass flux of $900 \mathrm{~kg} /\left(\mathrm{m}^{2} \mathrm{~s}\right)$

an increase in heat flux. This is due to a decrease in fluid viscosity and liquid density as temperatures in the fluid are increased.

For comparable junction temperature uniformity, the pressure drop of water is on the same order as that of the refrigerants. However, for EG, the pressure drops are about 1 order of magnitude larger than the refrigerants. It should be remembered that the micro-evaporators using refrigerants all have an extra pressure loss at the inlet due to the use of an orifice (included in the present calculations), which aids in stabilizing the flow. This orifice represents about $40-60 \%$ of the total pressure drop. The single-phase fluids do not have this loss, although some type of restriction would be required to prevent maldistribution, which would lead to higher pressure drops.

The pumping power requirements are shown in Fig. 15. An ideal pump was assumed with no losses, operating under isentropic conditions. As can be seen, the pumping power requirements for refrigerants HFC134a, HFO1234yf, HFO1234ze, and HFC236fa vary between 100 and $300 \mathrm{~mW}$, depending on the heat flux, while HCFC123 and HFC245fa require between 10 and $40 \mathrm{~mW}$. To comply with temperature uniformity requirements, the required pumping power for water would be on the order of $1300 \mathrm{~mW}$, while that of EG would be $13000 \mathrm{~mW}$. This is up to 20 and 130 times, respectively, higher than the requirements for some of the refrigerants. Note that even at these high mass fluxes for EG, the junction temperature (Fig. 12) is still higher than what can be obtained for some of the refrigerants, especially at high heat fluxes.

From an energetic point of view, Fig. 16 shows the ratio of total heat dissipated by the CPU to the cooling pumping power consumed for a mass flux of $900 \mathrm{~kg} /\left(\mathrm{m}^{2} \mathrm{~s}\right)$, except for water and $\mathrm{EG}$, which are at a mass flux of $3500 \mathrm{~kg} /\left(\mathrm{m}^{2} \mathrm{~s}\right)$ and $6000 \mathrm{~kg} /\left(\mathrm{m}^{2} \mathrm{~s}\right)$. Note that the units are in kilowatts per watt. Therefore, at the highest simulated base heat flux, HFC134a can extract over 2.5 $\mathrm{kW}$ of heat for every $1 \mathrm{~W}$ of pumping power. This, of course, is neglecting any auxiliary electronics to be cooled (memories for instance), piping, fittings, etc., which would add to the total pressure drop of the system. Note that CFC114 is energetically the best performing refrigerant for most of the low heat fluxes, after which HFC236fa becomes the best. Water and EG only extract $0.45 \mathrm{~kW} / \mathrm{W}$ and $0.05 \mathrm{~kW} / \mathrm{W}$ of pumping power at the highest base heat flux. It is important to mention that such comparison did not consider the same junction temperature uniformity (viz., Fig. 13). If the uniformity is limited to a maximum value of $2{ }^{\circ} \mathrm{C}$ for the whole range of base heat fluxes evaluated, the comparison presented in Figs. 13 and 16 can be made only between the working fluids HFO1234ze, HFO1234yf, HFC134a, water, and 50\%EG. In this way, when comparing two-phase with single-phase cooling, it

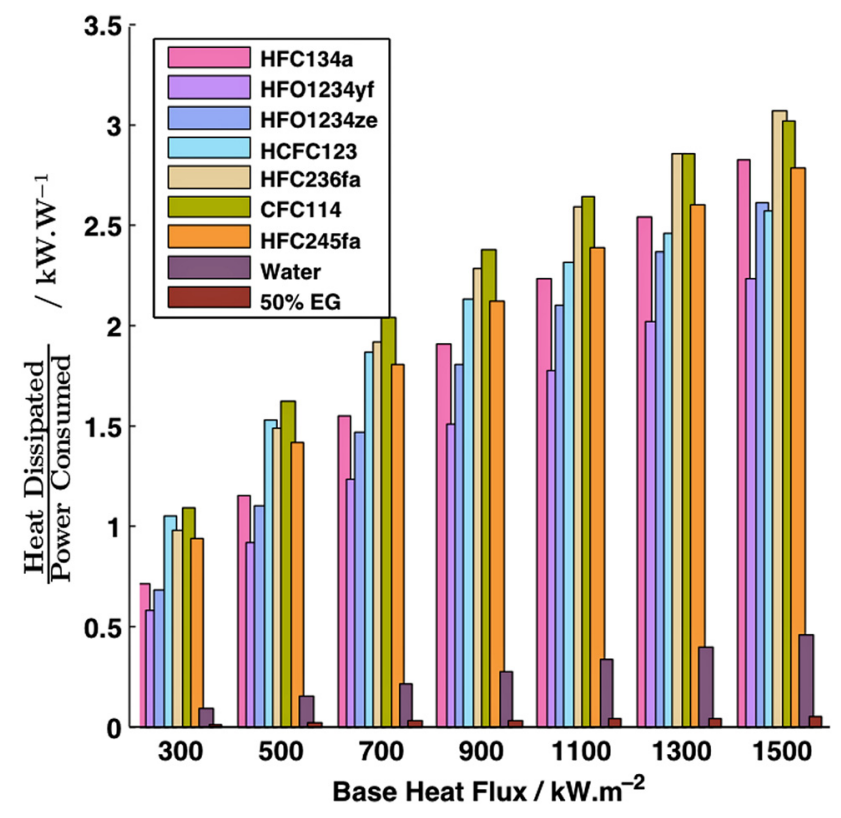

Fig. 16 Performance of the fluids at a mass flux of $900 \mathrm{~kg} /\left(\mathrm{m}^{2} \mathrm{~s}\right)$

is possible to say that HFC134a presents a much higher energetic performance than water.

4.3.4 Exergy and Energy Balance of a Liquid Pumping Cooling Cycle. To better evaluate the difference between single-phase and two-phase on-chip cooling by multimicrochannel elements (ME), the concept of exergy is introduced. A simplified cooling cycle composed of a liquid pump, a microevaporator, and a condenser is considered (viz., Fig. 17). The objective function is the exergetic efficiency associated with the exergy recovered in the condenser. For this analysis, the microprocessor, the component to be cooled, is defined as a uniform heat source of $400 \mathrm{~W}$ at $85^{\circ} \mathrm{C}$, while a counterflow heat exchanger is used as the condenser. The secondary fluid is water at an inlet and outlet temperature of $45^{\circ} \mathrm{C}$ and $55^{\circ} \mathrm{C}$, respectively. Olivier et al. [52] showed that, for energy recovery applications, $45^{\circ} \mathrm{C}$ is about the condenser outlet temperature of a coal power plant, being the potential point where the recovered heat of a datacenter can be injected. The pump is considered adiabatic and has an $80 \%$ isentropic efficiency.

Water and HFC134a are used as working fluids and an ME inlet temperature of $60^{\circ} \mathrm{C}$ is defined. For the water case, the ME inlet

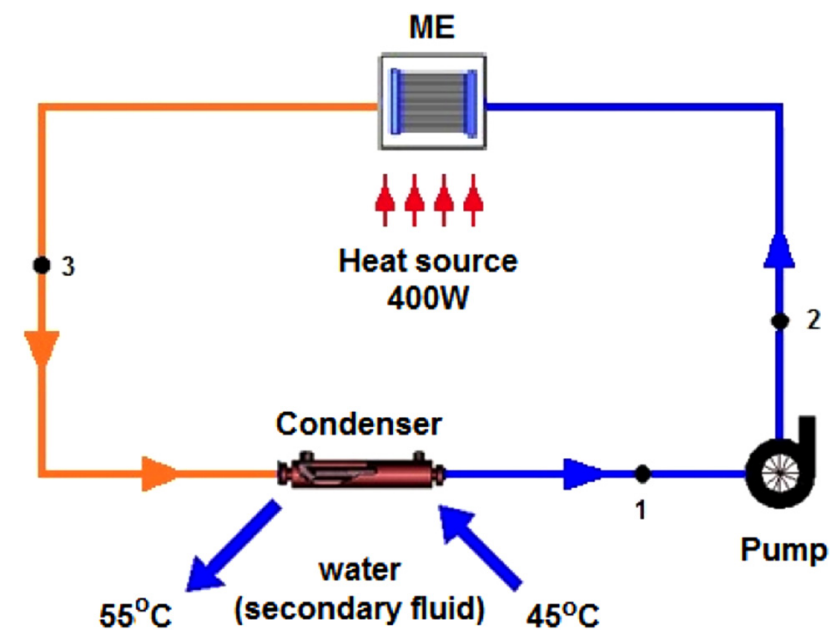

Fig. 17 Liquid pumping cooling cycle 
Table 2 Exergy and energy balance results

\begin{tabular}{|c|c|c|c|c|c|}
\hline \multicolumn{6}{|c|}{ Energy balance } \\
\hline Energy in & Water & HFC134a & Energy out & Water & HFC134a \\
\hline Pump input power (W) & 2.80 & 0.14 & Heat out in the condenser & 402.80 & 400.14 \\
\hline \multicolumn{6}{|c|}{ Exergy balance } \\
\hline & Water & HFC134a & & Water & HFC134a \\
\hline Exergy supplied (W) & 73.4 & 70.8 & Exergy recovered (W) & 35.1 & 35.0 \\
\hline $\begin{array}{l}\text { Exergy destroyed or } \\
\text { irreversibility (W) }\end{array}$ & & & Exergetic efficiency (\%) & & \\
\hline Pump & 0.50 & 0.02 & Pump & 82.3 & 82.3 \\
\hline Condenser & 13.1 & 10.9 & Condenser & 72.8 & 76.2 \\
\hline ME & 24.7 & 24.9 & $\mathrm{ME}$ & 65.1 & 64.8 \\
\hline Total & 38.3 & 35.8 & Overall & 47.8 & 49.4 \\
\hline
\end{tabular}

pressure and the increase of water temperature from inlet to outlet are considered to be $300 \mathrm{kPa}$ and $2{ }^{\circ} \mathrm{C}$ (defined as a limit to avoid high gradient of temperature on the microprocessors), respectively. For the HFC134a case, an ME outlet vapor quality of $30 \%$ is chosen. The mass flow rate of the working fluid and secondary fluid were adjusted so that the energy balance is respected. For these conditions, the simulations showed a pressure drop in the microevaporator of $23 \mathrm{kPa}$ and $6 \mathrm{kPa}$ for water and HFC134a cases, respectively. The same geometry of ME used in the previous simulations was considered here. The pressure drop in the condenser is considered the same as that for the ME.

The steady state exergy rate balance is defined by Eq. (2) [53]. The first and second terms in the right side of equality represent the exergy transfer accompanying heat and work, the third and fourth are the time rate of exergy transfer accompanying mass flow and flow work and, finally, the last term is the rate of exergy destroyed

$0=\underbrace{\sum_{j}\left(1-\frac{T_{0}}{T_{j}}\right) \dot{Q}_{j}-\dot{W}_{c v}+\sum_{i} \dot{m}_{i} e_{f i}-\sum_{e} \dot{m}_{e} e_{f e}}_{\text {rate of exergy transfer }}-\underbrace{\dot{E}_{d}}_{\begin{array}{c}\text { rate of } \\ \text { exergy }\end{array}}$ destruction

The parameters in the equation are defined as follows:

$T_{0}$-dead state temperature

$T_{J}$-instantaneous temperature

$Q_{j}$-heat transfer rate

$W_{c v}$-energy transfer rate by work

$\dot{m}_{i}, \dot{m}_{e}-$ inlet and outlet mass flow rate, respectively

$\dot{e}_{f i}, \dot{e}_{f e}-$ inlet and outlet flow exergies, respectively

$\dot{E}_{d}$-rate of exergy destruction due to irreversibilities within the control volume

It can be observed that an exergy reference environment is necessary to be defined. Such an environment represents the state of equilibrium or dead state. This equilibrium state defines the exergy as the maximum theoretical work obtainable when another system in a nonequilibrium state interacts with the environment to the equilibrium. For the present work, the reference is defined as $295 \mathrm{~K}, 100 \mathrm{kPa}$ for water and $295 \mathrm{~K}, 603.28 \mathrm{kPa}$ and $50 \%$ of vapor quality for HFC134a.

The goal of the analysis is to determine, for each case, the exergy supplied, recovered, and destroyed for a control volume in the cooling cycle. With this, the overall exergetic efficiency, defined as the ratio between recovered and supplied exergies, can be determined. The exergetic efficiency of each component, i.e., pump, condenser, and $\mathrm{ME}$, is also evaluated. It qualitatively identifies and classifies the components that present higher irreversibilities, helping to decide which component is to be optimized to improve the thermodynamic performance of the cooling cycle.

Table 2 shows the results obtained regarding exergy and energy. For this analysis, it is worth mentioning that the piping connecting the main components is considered to be adiabatic having no pressure losses, while the potential and kinetic energy effects in the cooling cycle are also neglected.

First, it can be seen that the total exergy destroyed, i.e., the irreversibility, is higher for the cooling cycle using water as a working fluid. Of the three components considered in the cooling cycle, the ME showed the highest irreversibility, which implies that, to improve the thermodynamic performance of the cooling cycle, the first component to be optimized in the design would be the ME. It is important to mention that since the simulation considered adiabatic pumping and the heat losses and pressure drops in the piping were neglected, it means that such an analysis is limited to the main components of the cycle and a complete simulation must to be done to generalize the conclusions.

It can also be observed that the overall exergetic efficiency is lower for the cycle using water as a working fluid, with the pump and condenser being the main culprits. The overall exergetic efficiency also shows that there is a huge need to improve the thermodynamic performance of the cooling cycle, since only $50 \%$ of the available exergy is used.

Figure 18 shows the exergetic efficiency as a function of the water temperature at the inlet of the condenser (secondary fluid). For this simulation, the outlet temperature of water was considered to be $60^{\circ} \mathrm{C}$, i.e., the maximum possible for the cycle proposed, and an energy efficiency of $100 \%$ (without heat losses). It can be seen that the exergetic efficiency increases when the inlet temperature of the water increases and the maximum value is about $65 \%$. The maximum possible value, $100 \%$, would be obtained when the inlet temperature of water approaches the source temperature $\left(85^{\circ} \mathrm{C}\right)$. It can be concluded that, for a proper utilization of exergy, it is desirable to have an energy efficiency as close to unit as practical while also having a good match between the source and the usage temperature (inlet and outlet water temperature-secondary fluid).

Finally, it is important mentioning that the thermodynamic performance alone (energy balance) does not permit the analysis showed beforehand. Exergy analysis clearly identifies efficiency improvements and reductions in thermodynamics losses attributable to green technologies. Additional advantages of such analysis are the potential to evaluate green technology aspects such as environmental impact or sustainable development (normally associated with carbon dioxide emissions) and economics ("exergy, not energy, is the commodity of value in a system, and assign costs and/or prices to exergy-related variables [54]"). 


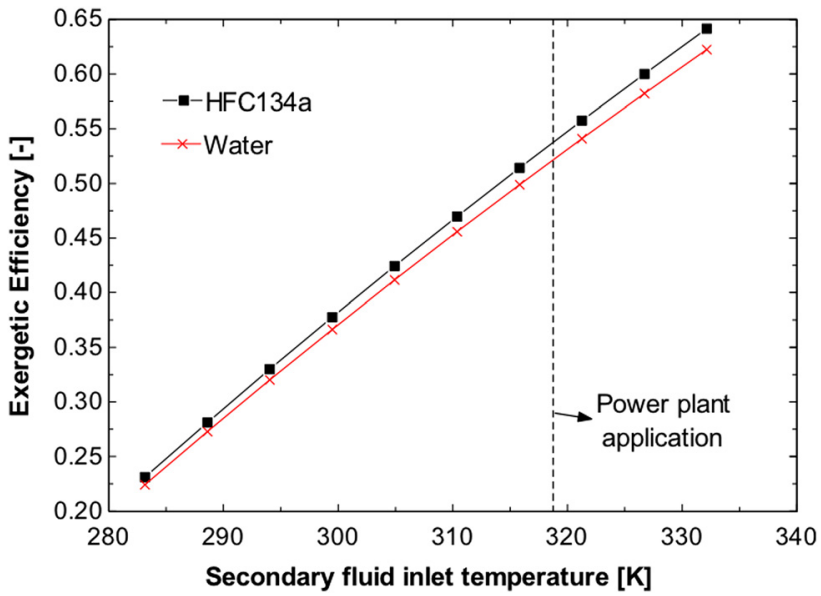

Fig. 18 Exergetic efficiency versus secondary fluid temperature

4.4 Hot-Spots. Nonuniform power dissipation across a chip leads to local hot-spots, resulting in elevated temperature gradients across the silicon die. These hot-spots could result in the degradation of reliability and performance of the chip [55], with a complete thermal breakdown of the chip also being possible. The reliability of a chip decreases by $10 \%$ for every $2{ }^{\circ} \mathrm{C}$ rise in temperature [56].

To simulate the effect the evaporator has on hot-spots, a case study with three hot-spots was developed. This is shown in Fig. 19, which is a two-dimensional view of the chip viewed from above, assuming a simple set of hot zones to illustrate the principle. Fluid flows over the chip from left to right. The three hotspots (in green) have a heat flux of $2000 \mathrm{~kW} / \mathrm{m}^{2}\left(200 \mathrm{~W} / \mathrm{cm}^{2}\right)$, while the remainder of the chip has a heat flux of $500 \mathrm{~kW} / \mathrm{m}^{2}(50$ $\mathrm{W} / \mathrm{cm}^{2}$ ). This results in $95 \mathrm{~W}$ of total heat that needed to be dissipated. Three fluids were simulated, namely HFC134a, water, and $50 \%$ water-ethylene glycol mixture. All the fluids had the same operating conditions as those in Sec. 4.3.2 except that the mass flux was maintained at $500 \mathrm{~kg} / \mathrm{m}^{2} \mathrm{~s}$.

From Sec. 4.3.2, the effect of heat flux on heat transfer coefficient was shown for two-phase and single-phase flows. This effect is also seen when plotting the local heat transfer coefficients as a function of the chip axial distance, as shown in Fig. 20. It is seen

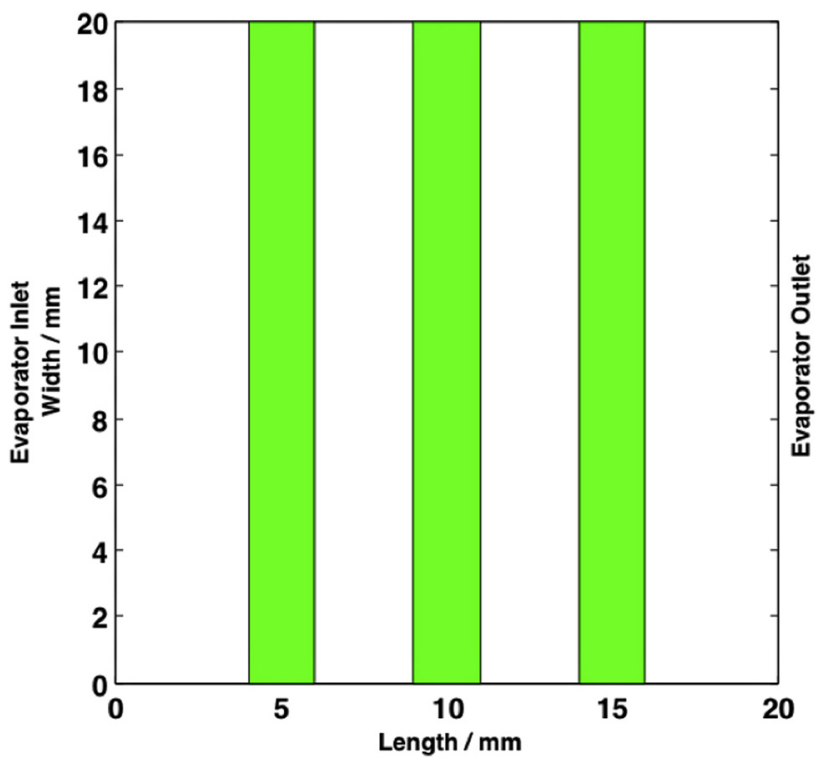

Fig. 19 Simulated hot-spot map

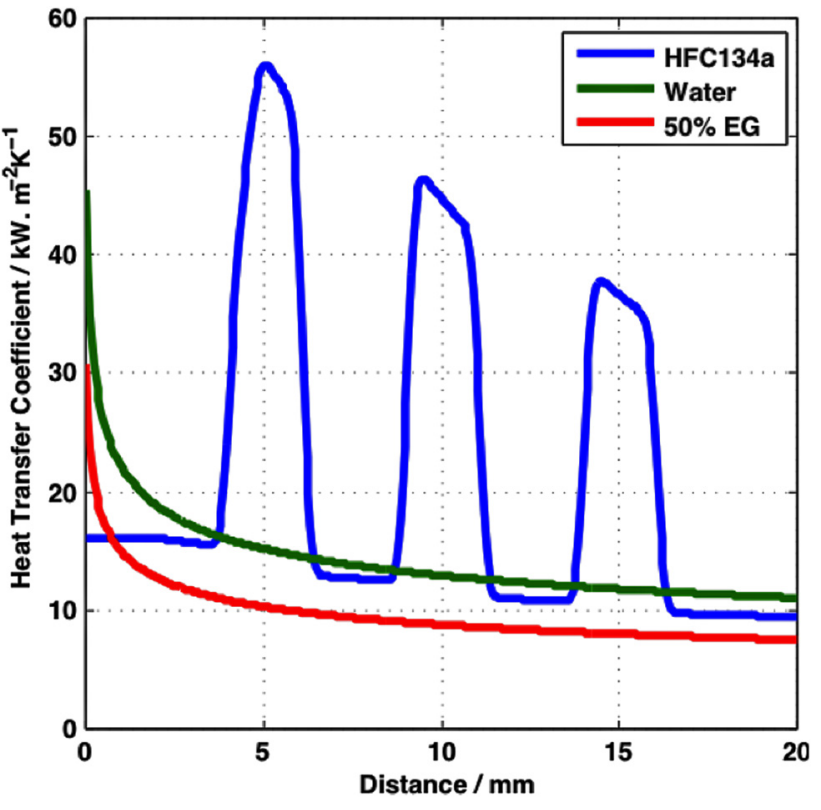

Fig. 20 Local heat transfer coefficient with hot-spots

that, for two-phase flow, the heat transfer coefficient reacts accordingly, which is not the case for single-phase flow.

This has a drastic effect on the junction temperature, as shown in Fig. 21. With two-phase flow, the peak temperature is $75^{\circ} \mathrm{C}$, while with water and EG the peaks are at $97^{\circ} \mathrm{C}$ and $106^{\circ} \mathrm{C}$, respectively, both beyond the operating limits of a CPU. This is $22^{\circ} \mathrm{C}$ and $33^{\circ} \mathrm{C}$, respectively, higher than that for HFC134a. For the single-phase fluids to attain the peak temperature as HFC134a, flow rates of more than 10 to 28 times for water and EG, respectively, are required, resulting in pumping power requirements of more than 81 and 1600 times that of HFC134a for the two singlephase fluids, respectively. When compared to two-phase flow, the reliability of the chip when using water or EG is reduced by more than $100 \%$ under the same operating conditions if a $10 \%$ decrease per $2{ }^{\circ} \mathrm{C}$ increase is considered.

From the numerous experimental data obtained in the last decade, various trends regarding microchannel two-phase flow

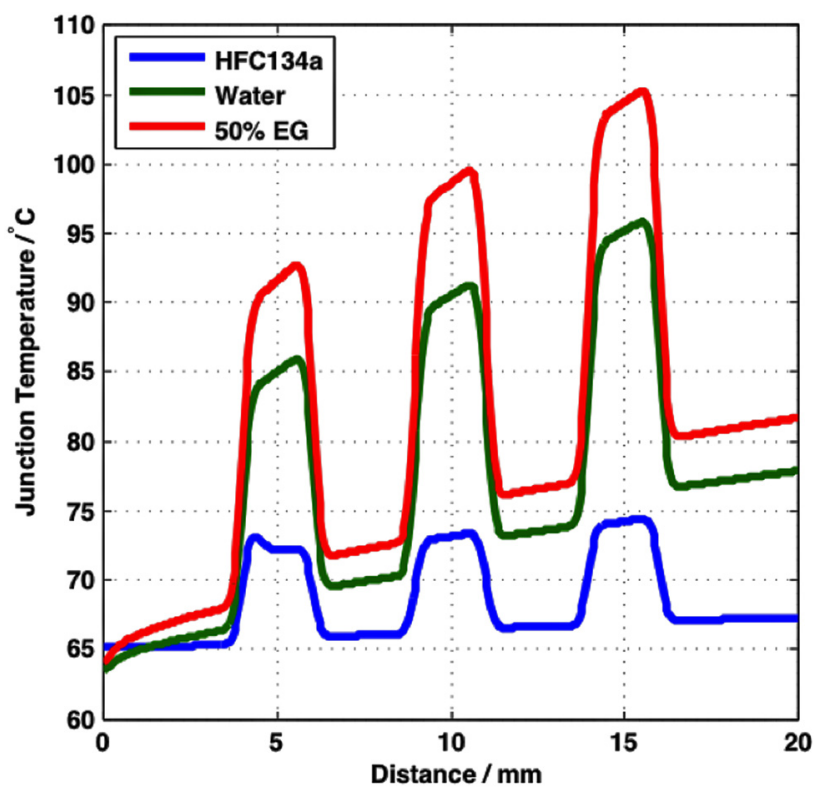

Fig. 21 Local junction temperatures with hot-spots 
boiling have been observed by Agostini and Thome [57]. One of these trends is that the local heat transfer coefficient for microchannel flow boiling at low to intermediate vapor qualities increases proportionally with the heat flux, essentially in the isolated bubble and coalescing bubble flow regimes but not in the annular flow regime as noted by Ong and Thome [58]. In general, it has been found that it approximately increases as $\alpha \propto \mathrm{q}^{0.7}$. More recent results by Costa-Patry et al. [33], focusing on cooling of hot-spots of a pseudochip with 35 local heaters and temperature sensors cooled with a silicon multimicrochannel evaporator, have shown that this proportionality is closer to $\mathrm{q}^{0.4}$, with conduction (heat spreading) effects within the evaporator being the main differentiating factor.

\section{Conclusion}

This paper presented some insight into the thermal issues of using single- and two-phase cooling inside multimicrochannel geometries for the cooling of microprocessors for green data centers. This was done by running simulations at fluid inlet temperatures of $60^{\circ} \mathrm{C}$ with the aim of maintaining junction temperature below $85^{\circ} \mathrm{C}$. These high working fluid temperatures are used so that the heat recovered can potentially be used for secondary, nondata center related processes, such as the heating of buildings, etc.

Simulations were performed for seven refrigerants for twophase cooling and for single-phase cooling water and a $50 \%$ water-ethylene glycol mixture. Heat fluxes and mass fluxes were varied from 200 to $1500 \mathrm{~kW} / \mathrm{m}^{2}$ and 300 to $1000 \mathrm{~kg} / \mathrm{m}^{2} \mathrm{~s}$, respectively. The mass fluxes of water and water-ethylene glycol mixture was varied between 300 and $6000 \mathrm{~kg} /\left(\mathrm{m}^{2} \mathrm{~s}\right)$.

Results showed that most of the fluids were able to maintain junction temperatures below $85^{\circ} \mathrm{C}$ for the range of heat fluxes. Only HCFC123 and CFC114 were unable to do so for heat fluxes greater than 1050 and $1250 \mathrm{~kW} / \mathrm{m}^{2}$, respectively, while the waterethylene glycol mixture was unable to do so for heat fluxes greater than $1400 \mathrm{~kW} / \mathrm{m}^{2}$. Junction temperatures for the remaining refrigerants were in general lower than those of the single-phase fluids. In fact, HFC134a had a $15^{\circ} \mathrm{C}$ lower temperature than the singlephase fluids. Only after the mass flow rates of the single-phase fluids were increased significantly did the junction temperatures become comparable.

Junction temperature uniformities for the refrigerants were also much better, except for HCFC123 and CFC114. For HFC134a, the variation in temperature never exceeded more than $1.8^{\circ} \mathrm{C}$, while for the single-phase fluids, this was approximately $5^{\circ} \mathrm{C}$. Only by increasing the single-phase fluid's flow rates by between 4 and 7 times that of the refrigerants did the variations become comparable.

It was shown that the increase in flow rate of the single-phase fluids required pumping power values of 20 and 130 times that of the refrigerant to obtain the same heat transfer performance. By comparing the ratio of heat removed from the CPU for every watt of pumping power required to cool it, water and the waterethylene glycol mixture had values of 0.45 and $0.05 \mathrm{~kW} / \mathrm{W}$ compared to the refrigerants having a value of about $2.5 \mathrm{~kW} / \mathrm{W}$. This shows that single-phase fluids require much more energy to remove the same amount of heat. This makes them very unattractive for a long-term green solution.

Exergy analyses were developed taking into account as objective function the exergy recovered in the condenser. A hypothetical cooling cycle composed by a pump, a condenser, and a multimicrochannel cooler was considered. The central idea was to prove the benefits of two-phase cooling when compared with single-phase not only by the energy balance (first thermodynamic law) mentioned beforehand but also by the exergy balance, which is based on the second thermodynamic law. In summary, the analyses showed that the overall exergetic efficiency of the two-phase cooling cycle was higher in about $2 \%$ regarding the single-phase cooling cycle. It was also possible to show that the cooling cycles presented a low overall exergetic efficiency (about 48-50\%), meaning that improvements can be done to increase the thermodynamic performance of the cycles. When looking for local effects, such analyses showed that the ME is the component with the lowest exergetic efficiency and would be the main component to be improved in terms of thermodynamic design. It is also relevant to say that such qualitative interpretation is only possible when the exergy analysis is considered.

Further simulations were performed for a chip having three hotspots. It was shown that two-phase refrigerant cooling was able to cope with hot-spots much better than single-phase cooling, with peak junction temperatures for the evaporator using refrigerant being 22 to $33^{\circ} \mathrm{C}$ lower than those using single-phase fluids. The reason why the refrigerants were able to handle the hot-spots is due to the two-phase heat transfer coefficient being proportional to the heat flux (approximately to the 0.7 power). Therefore, an increase in heat flux will result in an increase in heat transfer coefficient. This is not the case for single-phase heat transfer, where heat transfer coefficients are independent of heat flux. For the single-phase fluids to have similar peak junction temperatures to two-phase refrigerants, flow rates need to be increased by more than 10 to 28 times that of the refrigerant, with the respective pumping powers being 81 and 1600 times greater.

Therefore, making use of a two-phase refrigerant for the cooling of electronic equipment not only saves energy for the amount of heat extracted but also manages chip temperature and temperature variations better. This has the advantage for chips to be more reliable and to have a longer life span. The saved energy is also advantageous when heat recovery of a data center is of concern as less energy is required for cooling.

\section{References}

[1] EPA, 2007, Report to Congress on Server and Data Center Energy Efficiency Public Law 109-431, U.S. Environmental Protection Agency.

[2] Larson, J. B., 2009, America's Energy Security Trust Fund Act of 2009, in H.R. 1337.

[3] Koomy, J. G., 2007, Estimating Regional Power Consumption by Servers: A Technical Note, Lawrence Berkeley National Laboratory, Oakland, CA.

[4] IBM, 2007, IBM Unveils Plan to Combat Data Center Energy Crisis; Allocates \$1 Billion to Advance "Green" Technology and Services, http://www-03.ibm.com/press/us/en/pressrelease/21524.wss

[5] Leonard, P. L., and Phillips, A. L, 2005, "The Thermal Bus Opportunity-A Quantum Leap in Data Center Cooling Potential," ASHRAE Transactions, Denver, CO.

[6] Saini, M., and Webb, R. L., 2003, "Heat Rejection Limits of Air Cooled Plane Fin Heat Sinks for Computer Cooling," IEEE Trans. Compon. Packag. Technol., 26(1), pp. 71-79.

[7] Ellsworth, M. J., Jr., and Simons, R. E., 2005, "High Powered Chip CoolingAir and Beyond," Electron. Cooling, 11(3), pp. 14-22.

[8] CMOSAIC, 2010, "3D Stacked Architectures with Interlayer Cooling," http:// esl.epfl.ch/page78902-en.html

[9] Brunschwiler, T., Smith, B., Ruetsche, E., and Michel, B., 2009, "Toward ZeroEmission Data Centers Through Direct Reuse of Thermal Energy," IBM J. Res. Dev., 53(3), pp. 11:1-11:13.

[10] Chu, R. C., Simons, R. E., Ellsworth, M. J., Schmidt, R. R., and Cozzolino, V. 2004, "Review of Cooling Technologies for Computer Products," IEEE Trans. Device Mater. Reliability, 4(4), pp. 568-585.

[11] Agostini, B., Fabbri, M., Park, J. E., Wojtan, L., Thome, J. R., and Michel, B., 2007, "State-of-the-Art of High Heat Flux Cooling Technologies," Heat Transfer Eng., 28, pp. 258-281.

[12] Celata, G. P., Cumo, M., Guglielmi, M., and Zummo, G., 2002, "Experimental Investigation of Hydraulic and Single-Phase Heat Transfer in 0.130-mm Capillary Tube," Nanoscale Microscale Thermophys. Eng., 6, pp. 85-97.

[13] Celata, G. P., Morini, G. L., Marconi, V., McPhail, S. J., and Zummo, G., 2006, "Using Viscous Heating to Determine the Friction Factor in MicrochannelsAn Experimental Validation," Exp. Therm. Fluid Sci., 30, pp. 725-731.

[14] Celata, G. P., Cumo, M., McPhail, S. J., and Zummo, G., 2006, "Characterization of Fluid Dynamic Behaviour and Channel Wall Effects in Microtube," Int. J. Heat Fluid Flow, 27, pp. 135-143.

[15] Celata, G. P., Cumo, M., Marconi, V., McPhail, S. J., and Zummo, G., 2006, "Microtube Liquid Single-Phase Heat Transfer in Laminar Flow," Int. J. Heat Mass Transfer, 49, pp. 3538-3546.

[16] Tuckerman, D. B., and Pease, R. F. W., 1981, "High-Performance Heat Sinking for VLSI," IEEE Electron. Device Lett., EDL-2(2), pp. 126-129.

[17] Colgan, E. G., Furman, B., Gaynes, M., Graham, W. S., LaBianca, N. C., Magerlein, J. H., Polastre, R. J., Rothwell, M. B., Bezama, R. J., Choudhary, R., Marston, K. C., Toy, H., Wakil, J., Zitz, J. A., and Schmidt, R. R., 2007, “A Practical Implementation of Silicon Microchannel Coolers for High Power Chips," IEEE Trans. Compon. Packag. Technol., 30(2), pp. 218-225. 
[18] Colgan, E. G., Furman, B., Gaynes, M., LaBianca, N. C., Magerlein, J. H., Polastre, R. J., Bezama, R. J., Marston, K. C., and Schmidt, R. R., 2007, "High Performance and Subambient Silicon Microchannel Cooling," ASME J. Heat Transfer, 129, pp. 1046-1051.

[19] Ganapati, P., 2009, "Water-Cooled Supercomputer Doubles as Dorm Space Heater," available from: http://www.wired.com/gadgetlab/2009/06/ibmsupercomputer/

[20] Kandlikar, S. G., 2010, "Scale Effects on Flow Boiling Heat Transfer in Microchannels: A Fundamental Perspective," Int. J. Therm. Sci., 49(7), pp. 1073-1085.

[21] Kandlikar, S. G., and Balasubramanian, P., 2004, "An Extension of the Flow Boiling Correlation to Transition, Laminar, and Deep Laminar Flows in Minichannels and Microchannels," Heat Transfer Eng., 25(3), pp. 86-93.

[22] Kandlikar, S. G., 2004, "Heat Transfer Mechanisms During Flow Boiling in Microchannels," ASME J. Heat Transfer, 126(1), pp. 8-17.

[23] Celata, G. P., Saha, S. K., Zummo, G., and Dossevi, D., 2010, "Heat Transfer Characteristics of Flow Boiling in a Single Horizontal Microchannel," Int. J. Therm. Sci., 49(7), pp. 1086-1094.

[24] Bertsch, S. S., Groll, E. A., and Garimella, S. V., 2008, "Refrigerant Flow Boiling Heat Transfer in Parallel Microchannels as a Function of Local Vapor Quality," Int. J. Heat Mass Transfer, 51(19-20), pp. 4775-4787.

[25] Harirchian, T., and Garimella, S. V., 2008, "Microchannel Size Effects on Local Flow Boiling Heat Transfer to a Dielectric Fluid," Int. J. Heat Mass Transfer, 51, pp. 3724-3735.

[26] Lee, P. S., and Garimella, S. V., 2008, "Saturated Flow Boiling Heat Transfer and Pressure Drop in Silicon Microchannel Arrays," Int. J. Heat Mass Transfer, 51(3-4), pp. 789-806.

[27] Liu, D., Lee, P. S., and Garimella, S. V., 2005, "Prediction of the Onset of Nucleate Boiling in Microchannel Flow," Int. Commun. Heat Mass Transfer, 48(25-26), pp. 5134-5149.

[28] Bergles, A. E., and Kandlikar, S. G., 2005, "On the Nature of Critical Heat Flux in Microchannels," ASME J. Heat Transfer, 127, pp. 101-107.

[29] Wang, G., Cheng, P., and Bergles, A. E., 2008, "Effects of Inlet/Outlet Configurations on Flow Boiling Instability in Parallel Microchannels," Int. J. Heat Mass Transfer, 51(9-10), pp. 2267-2281.

[30] Thome, J. R., Dupont, V., and Jacobi, A. M., 2004, "Heat Transfer Model for Evaporation in Microchannels. Part I: Presentation of the Model," Int. J. Heat Mass Transfer, 47, pp. 3375-3385.

[31] Revellin, R., and Thome, J. R., 2008, "An Analytical Model for the Prediction of the Critical Heat Flux in Heated Microchannels," Int. J. Heat Mass Transfer, 51, pp. 1216-1225.

[32] Park, J. E., Thome, J. R., and Michel, B., 2009, "Effect of Inlet Orifice on Saturated CHF and Flow Visualization in Multi-Microchannel Heat Sinks," Twenty-Fifth Annual Ieee Semiconductor Thermal Measurement and Management Symposium, pp. 1-8.

[33] Costa-Patry, E., Olivier, J. A., and Thome, J. R., 2010, "Hot-Spot Effects on Two-Phase Flow of R245fa in $85 \mu \mathrm{m}$-Wide Multi-Microchannels," 16th International Workshop on Thermal Investigations of IC's and Systems, Barcelona, Spain.

[34] Zhang, T., Peles, Y., Wen, J. T., Tong, T., Chang, J., Prasher, R., and Jensen, M.K., 2010, "Analysis and Active Control of Pressure-Drop Flow Instabilitie in Boiling Microchannel Systems," Int. J. Heat Mass Transfer, 52, pp. $2347-$ 2360

[35] Zhang, T., Wen, J. T., Peles, Y., Catano, J., Zhou, R., and Jensen, M. K., 2010, "Two-Phase Refrigerant Flow Instability Analysis and Active Control in Transient Electronics Cooling Systems," Int. J. Multiphase Flow, 37(1), pp. 84-97.

[36] Park, J. E., 2008, "Critical Heat Flux in Multi-Microchannel Copper Elements With Low Pressure Refrigerants," Ph.D. thesis, École Polytechnique Fédérale de Lausanne, Switzerland.

[37] Madhour, Y., Olivier, J. A., Costa-Patry, E., Paredes, S., Michel, B., and Thome, J. R., 2011, "Flow Boiling of R134a in a Multi-Microchannel Hea Sink With Hotspot Heaters for Energy-Efficient Microelectronic CPU Cooling Applications," IEEE Trans. Compon. Packag. Technol., 1(6), pp. 873-883.

[38] Lemmon, E., Huber, M., and McLinden, M., 2007, NIST Standard Reference Database 23: Reference Fluid Thermodynamic and Transport Properties-
REFPROP, S.R.D. National Institute of Standards and Technology and Program, Gaithersburg, MD.

[39] Dupont, V., Thome, J. R., and Jacobi, A. M., 2004, "Heat Transfer Model for Evaporation in Microchannels. Part II: Comparison With the Database," Int. J. Heat Mass Transfer, 47(14-16), pp. 3387-3401.

[40] Cioncolini, A., Thome, J. R., and Lombardi, C., 2009, "Unified Macro-toMicroscale Method to Predict Two-Phase Frictional Pressure Drops of Annular Flows,” Int. J. Multiphase Flow, 35, pp. 1138-1148.

[41] Müller-Steinhagen, H., and Heck, K., 1986, "A Simple Friction Pressure Drop Correlation for Two-Phase Flow in Pipes," Chem. Eng. Prog., 20, pp. 297-308.

[42] Ong, C. L., 2010, "Macro-to-Microchannel Transition in Two-Phase Flow and Evaporation," Ph.D. thesis, École Polytechnique Fédérale de Lausanne, Switzerland.

[43] Ribatski, G., Wojtan, L., and Thome, J. R., 2006, “An Analysis of Experimental Data and Prediction Methods for Two-Phase Frictional Pressure Drop and flow Boiling Heat Transfer in Micro-Scale Channels," Exp. Therm. Fluid Sci., 31, pp. 1-19.

[44] Shah, R. K., and London, A. L., 1978, Laminar Flow Forced Convection in Ducts, Academic, New York.

[45] Thome, J. R., 2009, Engineering Data Book III, Wolverine Tube, Inc., Huntsville, AL.

[46] Montreal Protocol, 2000, The Montreal Protocol on Substances that Deplete the Ozone Layer. http://ozone.unep.org/Publications/MP_Handbook/Section_1.1 The Montreal_Protocol/

[47] Kyoto Protocol, 1998, United Nations Framework Convention on Climate Change. http://www.unfccc.int

[48] Nielsen, O. J., Javadi, M. S., Sulbaek, M. P., Hurley, M. D., Wallington, T. J., and Singh, R., 2007, "Atmospheric Chemistry of $\mathrm{CF}_{3} \mathrm{CF}=\mathrm{CH}_{2}$ : Kinetics and Mechanisms of Gas-Phase Reactions With $\mathrm{Cl}$ Atoms, $\mathrm{OH}$ Radicals, and $\mathrm{O}_{3}$," Chem. Phys. Lett., 439, pp. 18-22.

[49] Søndergaard, R., Nielsen, O. J., Hurley, M. D., Wallington, T. J., and Singh, R. 2007, "Atmospheric Chemistry of Trans- $\mathrm{CF}_{3} \mathrm{CH}=\mathrm{CHF}$ : Kinetics of the GasPhase Reactions With $\mathrm{Cl}$ Atoms, $\mathrm{OH}$ Radicals, and $\mathrm{O}_{3}$," Chem. Phys. Lett., 443, pp. 199-204.

[50] Brown, J. S., Zilio, C., and Cavallini, A., 2010, "Thermodynamic Properties of Eight Fluorinated Olefins,” Int. J. Refrigeration, 33, pp. 235-241.

[51] Agostini, B., Revellin, R., Thome, J. R., Fabbri, M., Michel, B., Calmi, D., and Kloter, U., 2008, "High Heat Flux Flow Boiling in Silicon Multi-Microchannels-Part III: Saturated Critical Heat Flux of R236fa and Two-Phase Pressure Drops,” Int. J. Heat Mass Transfer, 51(21-22), pp. 5426-5442.

[52] Olivier, J. A., Marcinichen, J. B., and Thome, J. R., 2010, “Two-Phase Cooling of Datacenters: Reduction in Energy Costs and Improved Efficiencies," 13th Brazilian Congress of Thermal Sciences and Engineering-ENCIT2010, Uberlandia, MG, Brazil.

[53] Moran, M. J., Howard, I., and Shapiro, N., eds., 2010, Fundamentals of Engineering Thermodynamics, 6th ed., John Wiley \& Sons, New York, pp. 1725.

[54] Rosen, M. A., Dincer, I., and Kanoglu, M., 2008, "Role of Exergy in Increasing Efficiency and Sustainability and Reducing Environmental Impact," Energy Policy, 36, pp. 128-137.

[55] Karajgikar, S., Agonafer, D., Ghose, K., Sammakia, B., Amon, C., and RefaiAhmed, G., 2010, "Multi-Objective Optimization to Improve Both Thermal and Device Performance of a Nonuniformly Powered Micro-Architecture," ASME J. Electron. Packag., 132, pp. 81-87.

[56] Bar-Cohen, A., Kraus, A. D., and Davidson, S. F., 1983, "Thermal Frontiers in the Design and Packaging of Microelectronic Equipment," Mech. Eng., 105(6), pp. 53-59.

[57] Agostini, B., and Thome, J. R., 2005, "Comparison of an Extented Database for Flow Boiling Heat Transfer Coefficients in Multi-Microchannels Elements With the Three-Zone Model," ECI Heat Transfer and Fluid Flow in Microscale, Castelvecchio Pascoli, Italy.

[58] Ong, C. L., and Thome, J. R., 2011, "Macro-to-Microchannel Transition in Two-Phase Flow: Part 2-Flow Boiling Heat Transfer and Critical Heat Flux," Exp. Therm. Fluid Sci., 35(6), pp. 873-886. 